\title{
University student conceptual resources for understanding energy
}

\author{
Hannah C. Sabo, ${ }^{*}$ Lisa M. Goodhew, ${ }^{\dagger}$ and Amy D. Robertson \\ Seattle Pacific University, Seattle, Washington, 98119-1997, USA
}

(Received 9 September 2015; published 4 April 2016)

\begin{abstract}
We report some of the common, prevalent conceptual resources that students used to reason about energy, based on our analysis of written responses to questions given to 807 introductory physics students. These resources include, for example, associating forms of energy with indicators, relating forces and energy, and representing energy quantitatively. This research responds to a need for large-scale, resourcesoriented research on students' conceptual understanding and has the potential to support the development of an underexplored dimension of pedagogical content knowledge-knowledge of student resources for understanding energy. Our aim is to promote instructor take-up of the resources theory of knowledge, and we suggest a number of ways in which instructors might capitalize on the resources we report.
\end{abstract}

DOI: 10.1103/PhysRevPhysEducRes.12.010126

\section{INTRODUCTION}

Constructivist science education research, generally speaking, takes as a premise that (a) learners have stores of ideas about the physical world [1-7] and that (b) these ideas affect future learning [8-11]. Although agreed upon this premise, science education researchers have taken very different stances toward the nature and structure of students' intuitive knowledge. In particular, the misconceptions and resources theories of knowledge have informed divergent research and instructional agendas. Table I summarizes these different stances, assumptions, and agendas.

While instructors and researchers need not ascribe to a single theory of knowledge (and while there is variation within researcher and instructor instantiations of these theories of knowledge), misconceptions research has had a more pronounced large-scale impact on the field of physics education research. It has produced an abundance of research delineating specific misconceptions (see, for example, compilations by Duit and Driver $[22,23,49])$, a host of curricula that aim to address common misunderstandings (e.g., [50,51]), and a cohort of instructors whose learning goals are shaped by the stances and assumptions of this theory of knowledge. The instructional impact of resources research has been less pronounced at the large scale, despite its potential to enhance students' conceptual understanding [52-60], provide opportunities for students to engage in disciplinary practices $[31,39,45,61-63]$, promote learner agency [63-67], and foster more equitable

\footnotetext{
*saboh@spu.edu

'goodhewl@spu.edu

robertsona2@spu.edu
}

Published by the American Physical Society under the terms of the Creative Commons Attribution 3.0 License. Further distribution of this work must maintain attribution to the author(s) and the published article's title, journal citation, and DOI. participation [65,68-73]. We suspect there are (at least) two reasons that resources theory has not recognized its potential impact:

(1) Limited large-scale research constrains buy-in to practical viability of resources theory of knowledge. Research about instruction that stems from the resources theory of knowledge has tended to focus on specific instances in which teachers notice and take up particular "seeds of science" [32] in their students' talk and action $[31,39,44,61,74,75]$. In part because the resources theory sees knowledge as flexible and dynamic-influenced by and influencing the instructional context-researchers are careful to avoid producing research that may lead to the static characterization of groups of students [21,76,77]. Instead, they emphasize attending to the specific ideas that emerge, in the moment, from classroom discourse. However, in a field (such as physics) that highly values the recurrence and reproducibility of results [78,79], buy-in to the practical viability of the resources theory of knowledge is limited in the absence of systematic, large-scale research that (i) articulates specific, recurring resources that students use during physics instruction and (ii) demonstrates the (large-scale) effectiveness of instruction that builds on and refines students' intuitions.

(2) Lack of support limits instructional take-up of resources theory of knowledge. Conceptualizations of pedagogical content knowledge (PCK) [80-84]—which includes knowledge of student ideas, knowledge of topic-specific instructional strategies, and curricular knowledge - are typically informed by the misconceptions theory of knowledge, rather than the resources theory. For example, researchers' characterizations of the "knowledge of student ideas" dimension of PCK emphasize common student misunderstandings about specific topics (see, e.g., Refs. [85-87] in physics), rather than students' productive intuitions. Similarly, research-based curricula that are available for teaching physics [50,51], tend to use 
TABLE I. Trends in stances, assumptions, and agendas of misconceptions and resources theories.

\begin{tabular}{lcc}
\hline \hline & Misconceptions theory & Resources theory \\
\hline $\begin{array}{l}\text { Stance toward students' } \\
\text { intuitive thinking }\end{array}$ & $\begin{array}{c}\text { Students' intuitive knowledge is inconsistent } \\
\text { with scientifically accepted views and } \\
\text { represents a barrier to the development of } \\
\text { canonically correct understanding [12-19]. }\end{array}$ & $\begin{array}{c}\text { Students' intuitive knowledge is consistent with } \\
\text { scientists' views in some contexts, and represents a } \\
\text { foundation for the development of scientifically } \\
\text { sophisticated understanding [10,20,21]. }\end{array}$ \\
$\begin{array}{l}\text { Assumptions about the } \\
\text { structure of } \\
\text { knowledge }\end{array}$ & $\begin{array}{c}\text { Student knowledge is rigid and coherent/ } \\
\text { context-independent [20,22-24]. }\end{array}$ & $\begin{array}{c}\text { Student knowledge is dynamic and context-dependent } \\
{[4,21,25,26] .}\end{array}$ \\
$\begin{array}{l}\text { Research agenda } \\
\text { Researchers search for common, incorrect } \\
\text { patterns in student reasoning ([15,27,28], } \\
\text { e.g., [17,29]). }\end{array}$ & $\begin{array}{c}\text { Researchers search for productive, potentially-useful } \\
\text { student ideas [30-33]. }\end{array}$ \\
& $\begin{array}{c}\text { Instruction should elicit, confront, and resolve } \\
\text { misconceptions [15,16,24,27,34-38]. }\end{array}$ & $\begin{array}{c}\text { Instruction should build on and refine students' } \\
\text { intuitions [4,5,32,35,39-48]. }\end{array}$ \\
\hline \hline
\end{tabular}

instructional strategies more consistent with thinking of students' intuitive ideas as misconceptions (e.g., elicit, confront, resolve). ${ }^{1}$ Knowledge of resources that students commonly use to reason about specific physics topics, instructional strategies that build on these resources, and curricula that are consistent with the resources theory of knowledge are viable starting places for instructional takeup of the resources theory of knowledge. Unfortunately, there is very little in the way of research or curriculum that would directly inform this take-up. ${ }^{2}$

Our paper responds to the need for instructor buy-in and take-up of the resources theory of knowledge by (i) conducting systematic, large-scale research on the specific, recurring conceptual resources that university physics students use to reason about energy and by (ii) suggesting instructional implications of our work that capitalize on students' intuitive understandings of energy. We seek to answer the following research question:

What are some of the recurrent, prevalent conceptual resources used by university physics students when reasoning about energy?

To answer this question, we developed and administered written questions about energy to more than 800 introductory physics students from six universities across the United States. We analyzed their responses to these questions, seeking to discern patterns of resource use in student reasoning about energy. In particular, we looked for

\footnotetext{
${ }^{1}$ One notable exception to this is the Maryland Open-Source Tutorials (see http://www2.physics.umd.edu/ elby/CCLI/index .html), which use "Elby pairs" [130] to refine students' intuitions about physics concepts.

${ }^{2}$ Notable exceptions in science (that include some physics examples) include Becoming a Responsive Science Teacher [46] and the "Responsive Teaching in Science" website (see http:// cipstrends.sdsu.edu/responsiveteaching/index.html).
}

resources that we could frame as "seeds" of canonical thinking, sophisticated reasoning, or scientific practices, such that an instructor could conceivably build on these ideas toward an instructional goal. We found that across instructional contexts, students frequently

- accounted for energy transfers and transformations in a scenario,

- associated (i) forms of energy with indicators and (ii) changes in energy with indicators of change,

- related energy to forces or work,

- implicitly used the second law of thermodynamics to reason about thermal energy transfer or energy degradation, and

- quantitatively represented energy.

The structure of student knowledge, according to resources theory, is dynamic and context dependent $[4,21,25,26]$, such that a researcher or instructor should not expect $a$ priori for a resource activated in one context to be activated in another. However, our claim that instructors can build on the resources we report relies, in part, on the context independence of particular student resources. Our response to this theoretical incongruity is twofold. First, the specific resources we report in this paper are ones that were activated in multiple contexts - across questions that we asked, for many students, in multiple different university courses. This suggests that such resources are common and may be more likely to be activated in a representative or average instructional context. Second, our primary goal in reporting student resources for understanding energy is to foster instructor attention to resources and to promote instructional practices consistent with the resources theory of knowledge. The intention is to enhance instructor awareness [77,88], rather than to predict the fraction of student ideas that will fit into any particular category, in which case the prevalence of a given resource is less important.

We chose to study student resources for understanding energy (rather than, for example, electricity or waves) for 
several reasons. Perhaps most importantly, energy is a concept with multidisciplinary relevance; it is fundamental to understandings of chemistry, biology, and physics, cutting across concepts in each of these disciplines [89-94]. In addition, although most of the existing literature on students' ideas about energy focuses on misconceptions (see Sec. II), there have been some recent efforts in identifying student resources for understanding energy. We wish to add to this literature, hoping to create a critical mass of research that can support instructors in building on student ideas about energy. Finally, we wished to capitalize on the collective expertise of our project team, comprised of researchers who have studied student and teacher learning about energy in multiple contexts [95-100].

\section{EXISTING STUDIES OF STUDENT IDEAS ABOUT ENERGY}

Our study builds on the efforts of many researchers who have investigated student ideas about energy. Some have investigated these ideas in a more general way, looking for what students commonly associate with energy or the frameworks that students use for understanding energy [101-108]. Other researchers have investigated student understanding of particular facets of the energy concept, such as gravitational energy [109,110], conservation $[111,112]$, or metaphors for energy [113-116]. Themes in this literature include

- Students associate energy with human activity or with animate objects [101,103,105,106,117-119]. Many researchers report that students think of energy in terms of human activities or as necessary for life. Often, students list human activities (such as playing sports, manual labor, or basic life functions) as examples of energy. When asked to identify the energy involved in scenarios that include humans, some students focus on the energy associated with the human and overlook the energy associated with inanimate objects. This "anthropocentric/anthropomorphic" idea of energy is reported mainly in younger populations, and there is some suggestion that students move away from this idea with age [107].

- Students associate energy with obvious activity, especially movement $[101,106,107,117,118]$. Some researchers have found that students associate energy with obvious activity. Sometimes, students treat the activity as the energy, rather than as andicator of energy.

- Students think of energy as a substance that flows and transfers. Many report that students commonly think of energy as a material or quasimaterial substance $[33,101,107,113-118,120]$. There is debate over whether this particular idea is productive: some argue that this idea is a misconception because energy is not a material substance [121,122], while others argue that this is a productive metaphor used not only by learners but also by experts [2,114,115,123].

- Students treat energy as a fuel or stimulus [101,105,107,108,113,117,124,125]. Many studies have shown that students think of energy as a fuel $[105,119]$, as causing or necessary for activity or observable change $[115,117,118]$, or as a causal ingredient $[102,103,107]$. Trumper describes this as the "active deposit" framework, where students see energy as an ingredient that catalyzes change, motion, or action. A common manifestation of the idea of energy as a fuel or stimulus is the association of energy with technology or machines $[104,106,124]$. Some authors see the idea of energy as fuel as an alternative framework or naive preconception $[101,119]$, while others argue that this is a productive metaphor upon which a sophisticated understanding of energy can be built $[105,113,115]$.

- Students think of energy as used up, or they separate everyday and scientific understandings of energy. Many have written that students think of energy as being used up rather than conserved [1,107,110,124]. Some researchers report that students often have two modes for thinking about energy: one is the everyday sense of the word, in which energy is thought of as used up, as associated with human work, or as needing to be guarded against waste (the colloquial sense of "conserved"). The other is the scientific conception of energy, in which the amount of energy in any closed system is always conserved. Many of the studies reporting these trends find that students are more likely to rely on everyday definitions than scientific ones $[1,104,124,125]$.

- Students misunderstand or do not use the second law of thermodynamics. Some researchers find that students do not use the second law of thermodynamics to analyze physical scenarios $[108,126]$. For example, Duit found that students do not mention energy degradation when thinking about energy, and Vigeant et al., report that students tend to explain inefficiencies in thermodynamic systems with friction or lack of insulation rather than the second law.

Much of the literature about these and other student ideas about energy frames them as misconceptions - the authors focus on what students do not understand about energy or on which facets of the energy concept are particularly difficult for students $[109,110,116-118,127,128]$. These studies are often less concerned with what students do understand, and they rarely unpack why a particular idea might make sense to students or how these ideas might be the beginnings of more sophisticated understandings.

Others, such as Watts, investigate students' "alternative frameworks" or "naive preconceptions" about energy $[101,103,104]$. Unlike misconceptions researchers, these researchers tend to discuss the ideas that students do have 
about energy in more depth and detail. Still, such research tends to hold students' ideas up against the canon and point out how the ideas are different than the scientific concept.

Some have taken a neutral stance toward students' energy ideas [104,106,115]. These researchers simply articulate what students think without comparing their ideas to a canonical understanding of energy or evaluating how productive these ideas might be for developing such an understanding.

Still others view students' ideas as seeds of the scientific concept of energy, or as resources from which to develop a more sophisticated understanding. The resources perspective understands students' ideas to be inherently sensible and productive and argues that by encouraging investigation and sense making, teachers can foster growth in students' scientific ideas [105]. To our knowledge, the majority of the literature that takes a resources stance toward student ideas about energy reports instructional strategies, representations, or tools that can tap into or act as resources for students. For example, Trumper [102] reports that students tend to think about energy either as a stimulus that makes something happen or as a product of a process. Although these are incomplete frameworks, Trumper describes how these two student ideas can be combined into a more complete, scientific idea. Daane [1,124] argues that foregrounding the second law of thermodynamics in instruction can act as a bridge between learners' everyday ideas about energy and the scientific concept of energy (energy is conserved). Other researchers have investigated the resources afforded by particular representations of energy transfers and transformations [120,129].

In our study, we draw from and add to these different ways of understanding students' ideas about energy. Misconceptions research has characterized a number of ideas that students use when thinking about energy, but only those that are scientifically inaccurate, "alternative," or confusing to students. Resources research has described ways to frame instruction or instructional tools that tap into students' conceptual resources, but has only characterized student thinking about energy for small samples of students, which limits buy-in in the recurrence-oriented culture of physics. Using the tools of misconceptions research and the perspective of the resources theory of knowledge, we intend to promote instructor buy-in and take-up of the resources theory of knowledge by reporting the common, prevalent ideas used by students to reason about energy.

\section{RESEARCH METHODS}

In answering our research question, "What are some of the recurrent, prevalent conceptual resources used by university physics students when reasoning about energy?," we sought to make population-level claims-claims about what an instructor might expect of (or see in) student responses in an "average" physics course. In the absence of a representative sample of university physics students, writ large, we used a model of generalization "that emphasizes how consistently" a pattern "reproduces across multiple sources of heterogeneity" [78]. This model of generalization guided our research design: we sought patterns in student reasoning that emerged in response to questions that elicited reasoning about different facets of the energy concept, among students from many different courses across the United States. In other words, we intentionally diversified our question contexts and our samples in order to generate a data set that represents heterogeneity but maintains the target phenomenon of university physics student reasoning about energy.

Throughout our analysis, we used the resources theoretical framework $[6,21,26,130]$ described above. We framed students' reasoning as sensible and potentially productive - as reasonably following from their own experiences. Our question design was informed by this lens: the context for each question is linked to everyday experiences such as carrying books or pushing boxes, because we expected that these scenarios would provide access for many different students. Similar to Hammer, Goldberg, and Fargason [31], we chose questions that we expected "to be generative of many productive possibilities," and we felt that this generativity, in part, lies in how accessibly students can marshal their own experiences for sense-making purposes. The resources theoretical framework also informed our analysis: we looked for "seeds of science" [32] embedded within students' answers to our questions, searching out possible starting places for understanding important energy ideas. We developed an emergent coding scheme, in part, so that our analytical categories would reflect the resources that students were using in answering our questions (as opposed to those we hoped or expected them to use), reflecting our assumption that students bring appropriate and productive ideas to their sense-making about energy.

In the following sections, we lay out the specifics of our research methods, including our question design and validation, data collection, and data analysis techniques.

\section{A. Question design and validation}

For this study, we used a total of five conceptual questions to probe students' understanding of energy.

David is helping his friends move into a third-floor apartment and carries a box of books up two flights of stairs.

If you were asked to figure out how much energy David gave the books as he carried the box up the stairs, what would you do and what

additional information would you need? Describe any equations you would use and why using those equations makes sense to you. If you think David doesn't give the books any energy as he carries the box upstairs, say this explicitly and explain why you think so.

FIG. 1. David walks up stairs question. 


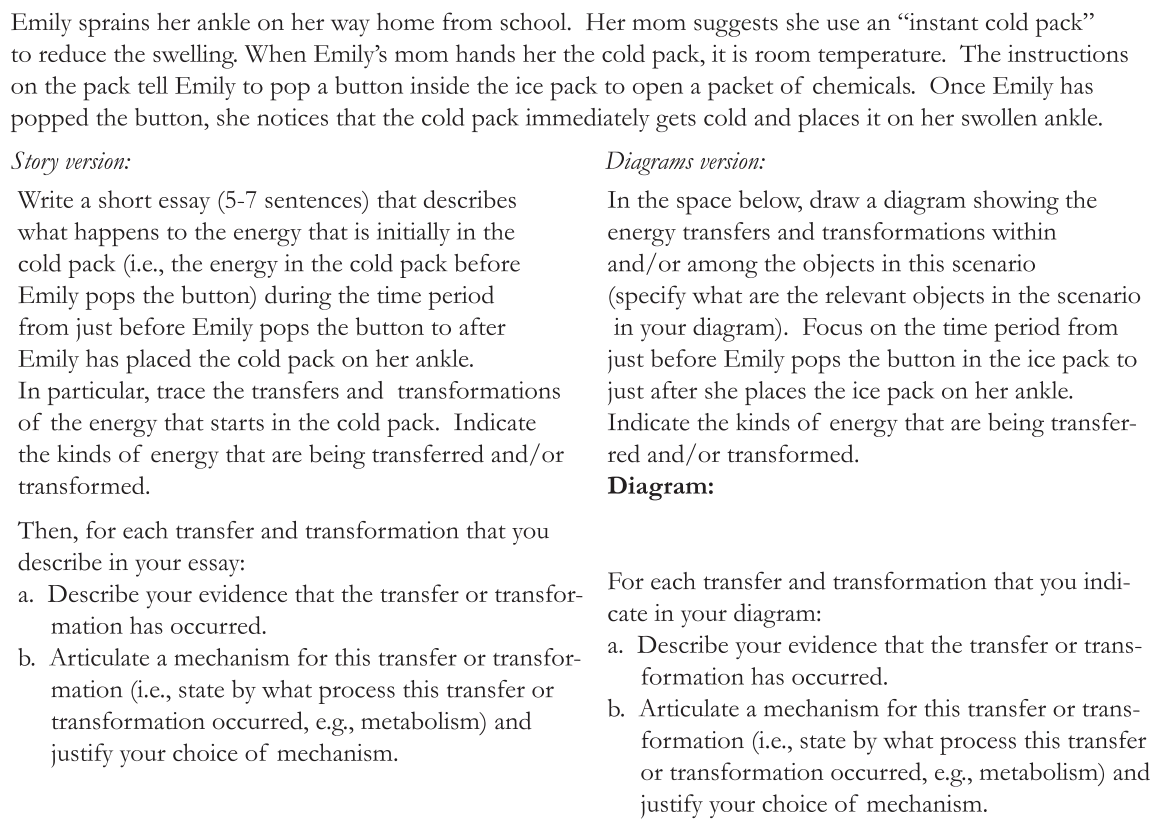

Write a short essay (5-7 sentences) that describes what happens to the energy that is initially in the cold pack (i.e., the energy in the cold pack before Emily pops the button) during the time period from just before Emily pops the button to after Emily has placed the cold pack on her ankle. In particular, trace the transfers and transformations of the energy that starts in the cold pack. Indicate the kinds of energy that are being transferred and/or transformed.

Diagrams version:

In the space below, draw a diagram showing the energy transfers and transformations within and/or among the objects in this scenario (specify what are the relevant objects in the scenario in your diagram). Focus on the time period from just before Emily pops the button in the ice pack to just after she places the ice pack on her ankle. Indicate the kinds of energy that are being transferred and/or transformed.

Diagram:

Then, for each transfer and transformation that you describe in your essay:

a. Describe your evidence that the transfer or transformation has occurred.

b. Articulate a mechanism for this transfer or transformation (i.e., state by what process this transfer or transformation occurred, e.g., metabolism) and justify your choice of mechanism.

For each transfer and transformation that you indicate in your diagram:

a. Describe your evidence that the transfer or transformation has occurred.

b. Articulate a mechanism for this transfer or transformation (i.e., state by what process this transfer or transformation occurred, e.g., metabolism) and justify your choice of mechanism.

FIG. 2. Emily sprains her ankle question.

These questions were designed to be open ended, to connect formal physics concepts to everyday experiences such as pushing or carrying objects, and to encourage students to show their thinking processes in addition to their answers. The set of questions as a whole was intended to elicit student ideas about multiple different facets of the energy concept; our choice of five was motivated by the range of ideas the questions were designed to elicit. The David walks up stairs question (David question, Fig. 1) was designed to elicit students' ideas about the relationship between work and changes in energy, and to display how students translate scenarios into equations that they can solve. The Emily sprains her ankle (Emily question, Fig. 2) and the box on a spring (Fig. 3) questions were developed to investigate student ideas about energy transfers and transformations. The Bowling ball (Fig. 4) and Sarah pushes a box (Fig. 5) free body diagram questions were designed to elicit student ideas about the relationship

\footnotetext{
One end of a spring is attached to a flat ceiling and the other end of the spring is attached to a box, which is originally being held in place by a person's hand. After the person releases the box, the box moves toward the floor and the spring stretches.

Story version:

Write a short essay (5-7 sentences) that describes what happens to the energy that is initially in the box (i.e., the energy in the box when the person releases it) during the time period that the block is speeding up as it moves toward the floor. In particular, trace the transfers and transformations of the energy that starts in the box. Indicate the kinds of energy that are being transferred and/or transformed.

Diagrams version:

Draw a diagram showing the energy transfers and transformations within and/or among the objects in this scenario (specify what are the relevant objects in the scenario in your diagram) during the time period that the block is speeding up as it moves toward the floor. Indicate the kinds of energy that are being transferred and/or transformed.

Diagram:

Then, for each transfer and transformation that you describe in your essay:

a. Describe your evidence that the transfer or transformation has occurred.

b. Articulate a mechanism for this transfer or transformation (i.e., state by what process this transfer or transformation occurred, e.g., metabolism) and justify your choice of mechanism.

For each transfer and transformation that you indicate in your diagram:

a. Describe your evidence that the transfer or transformation has occurred.

b. Articulate a mechanism for this transfer or transformation (i.e., state by what process this transfer or transformation occurred, e.g., metabolism) and justify your choice of mechanism.
}

FIG. 3. Box on a spring question. 
Taylor lowers a bowling ball at constant speed from height h1 to height $\mathrm{h} 2$.

a. In the box at right, draw a free body diagram showing the forces acting on the bowling ball as it is lowered. In the space below, explain

how you decided what forces to include, and justify the relative magnitudes of the forces.

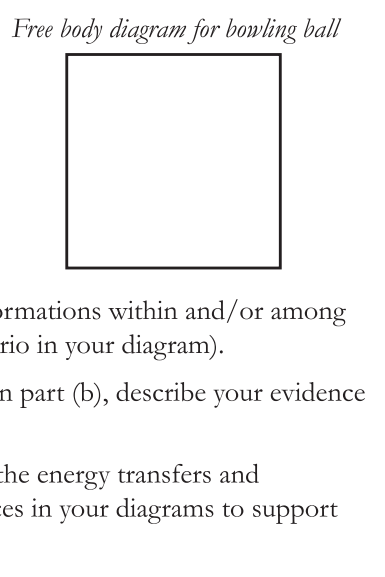

FIG. 4. Bowling ball free body diagram question.

between forces and energy. Possible answers for each question are given in the Appendix.

This set of questions underwent an extensive design and validation process, illustrated in Fig. 6 and described in what follows. Originally, we developed a set of ten questions to elicit specific aspects of students' conceptual understanding of energy, such as energy transfers and transformations or the relationship between work and changes in energy. We sent this original set of questions to physics education research faculty at Seattle Pacific University (SPU) for feedback on the clarity and face validity [131] (i.e., faculty and researchers' sense of whether the questions would elicit the intended ideas about energy) of each question. On the basis of this feedback, we narrowed our sample of questions and clarified aspects of the remaining questions. We then conducted validation interviews with a convenience sample of eleven introductory physics students from Seattle Pacific University and

Sarah pushes a box at constant speed across the floor.

a. In the box at right, draw a free body diagram showing the forces acting on the box as it moves across the floor. In the space below, explain how you decided what forces to include, and justify the relative magnitudes of the forces.

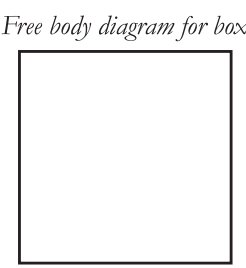

b. In the space below, draw a diagram showing the energy transfers and transformations within and/or among the objects in this scenario (specify what are the relevant objects in the scenario in your diagram).

c. For each of the transfers and transformations you indicate in your diagram in part (b), describe your evidence that the transfer or transformation has occurred.

d. How are the forces you drew in your free body diagram [part (a)] related to the energy transfers and transformations you drew in your diagram in part (b)? Point to specific places in your diagrams to support your answer.

FIG. 5. Sarah pushes a box free body diagram question.

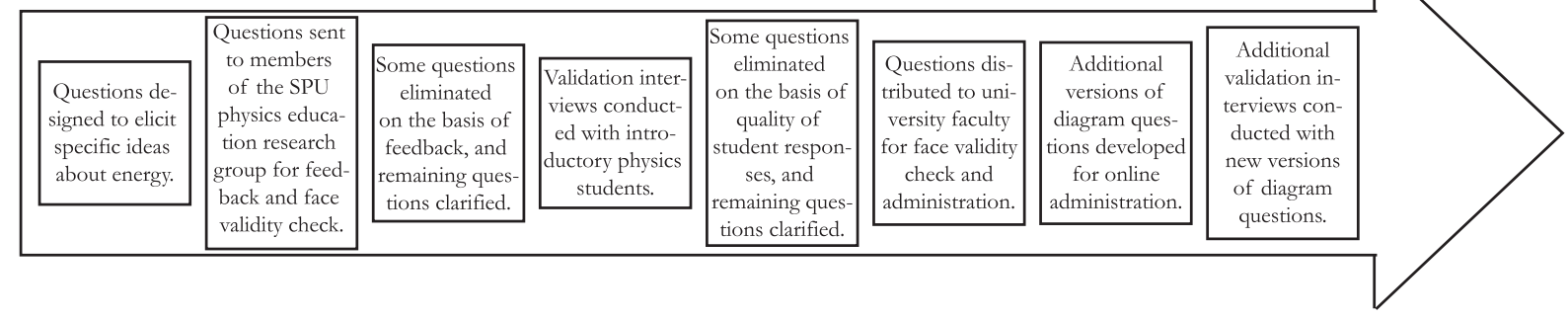

FIG. 6. Question design and validation process. 
TABLE II. Number of validation interviews conducted for each question.

\begin{tabular}{lc}
\hline \hline Question & $\begin{array}{c}\text { Number of students who } \\
\text { answered each question } \\
\text { in validation interviews }\end{array}$ \\
\hline David walks up stairs question & 5 \\
Emily sprains her ankle question & \\
$\quad$ Story version & 2 \\
$\quad$ Diagram version & 5 \\
Box on a spring question & 3 \\
$\quad$ Story version & 5 \\
$\quad$ Diagram version & 5 \\
Bowling ball free body & \\
diagram question & 4 \\
Sarah pushes a box free body & \\
diagram question & \\
\hline \hline
\end{tabular}

the University of Colorado-Boulder, for the purposes of understanding how students interpreted our remaining questions. (See Table II for the number of students who answered each question in validation interviews.) On the basis of these validation interviews, we further clarified the wording of some of our questions, and we eliminated two additional questions that we felt did not give us sufficient insight into student thinking about energy. We divided our final five questions into sets of two or three, and we sent these pairs and trios to university faculty teaching introductory physics courses at Baylor University, DePaul University, Penn State University-Greater Allegheny, Seattle Pacific University, the University of Maryland, and Western Washington University. These university faculty conducted an additional face validity check before giving the questions to their students. We learned at this stage that some instructors would be administering our questions in an online assignment, so we adapted two questions (the Emily and box-on-a-spring questions) so that instead of drawing diagrams representing energy transfers and transformations in specific scenarios, students were asked to write a short essay describing what happens to the energy that is initially in a specified object in the system. We then conducted additional validation interviews for these essay versions of our original problems.

\section{B. Sample}

Participants in this study were students in introductory algebra- and calculus-based physics courses at Baylor University, DePaul University, Penn State UniversityGreater Allegheny, Seattle Pacific University, the University of Maryland, and Western Washington University. Course sizes ranged from 30 to 278 students, and the courses were comprised of mostly engineering, physical sciences, and life sciences majors.

\section{Data collection}

Together the five questions illustrated by Figs. 1-5 were administered to 807 students at six universities. (See Table III for the samples that received each question.) The questions were included on in-class surveys, quizzes, and tests, as well as homework assignments outside of class. (See Table III for administration contexts and incentives for participation.) For the most part, nearly all of the students in each course responded to the questions (see Table III), mitigating concerns of a skewed sample. In all cases but one (Western Washington University), students completed the questions after all relevant energy instruction.

\section{Data analysis}

We began analyzing our data by developing emergent coding schemes [132] for each question. Categories in each coding scheme identified resources-or "seeds of science"- that students were using to reason about energy. All three of us individually developed a preliminary scheme for each question by reading through a subset of student responses and identifying productive beginnings of energy ideas within. For example, in an original inspection of the Emily question, Goodhew identified the following student response as associating energy forms with indicators (kinetic energy with motion): "Before the cold pack is activated, the water has kinetic energy because it is a liquid, where molecules freely slide around one another." After developing our own schemes for each question, we met to collaboratively negotiate the final version of each coding scheme, choosing to include those resources that appeared on multiple individual lists and debating the inclusion of those that were not.

Once we had developed coding schemes for all five questions, we noticed significant overlap in the resources students were using across questions, so we collapsed our single-question coding schemes into a scheme for the entire data set. Using this overarching scheme, Sabo and Goodhew individually coded each student response. A single student response was often given more than one code to represent the full range of resources that a student was using in their answer to a given question. After the entire data set had been coded, Robertson compared the codes that Sabo and Goodhew individually assigned to each response, keeping only those codes that were assigned by both, such that the final codes assigned to a single response reflected $100 \%$ agreement between coders. From here, we calculated the percentage of student responses that reflected each resource. Because these percentages represent the fraction of responses that two independent coders saw as reflecting a given resource, they likely reflect an underestimate of what a single instructor might see in a similar set of data. 
TABLE III. Samples that received each written question.

\begin{tabular}{|c|c|c|c|c|c|c|}
\hline Question & University & $\begin{array}{l}\text { Introductory } \\
\text { physics course }\end{array}$ & $\begin{array}{l}\text { Pre- or } \\
\text { postinstruction }\end{array}$ & $\begin{array}{l}\text { Administration context } \\
\text { and incentive for } \\
\text { participation }\end{array}$ & $\begin{array}{l}\text { Sample } \\
\text { size }\end{array}$ & $\begin{array}{c}\text { Fraction of } \\
\text { course who } \\
\text { participated } \\
\text { in study }\end{array}$ \\
\hline \multirow[t]{3}{*}{$\begin{array}{l}\text { David walks up } \\
\text { stairs question }\end{array}$} & Baylor University & Algebra-based & Postinstruction & $\begin{array}{l}\text { Graded online } \\
\text { homework } \\
\text { assignment }\end{array}$ & $N=125$ & $90 \%$ \\
\hline & $\begin{array}{l}\text { Penn State University- } \\
\text { Greater Allegheny }\end{array}$ & Calculus-based & Postinstruction & $\begin{array}{l}\text { Online homework } \\
\text { assignment, } \\
\text { participation points }\end{array}$ & $N=17$ & $57 \%$ \\
\hline & $\begin{array}{l}\text { Western Washington } \\
\text { University }\end{array}$ & Calculus-based & Pre-instruction & $\begin{array}{l}\text { Out-of-class pre-lab, } \\
\text { participation points }\end{array}$ & $N=229$ & $98 \%$ \\
\hline \multicolumn{7}{|l|}{$\begin{array}{l}\text { Emily sprains her } \\
\text { ankle question }\end{array}$} \\
\hline \multirow[t]{3}{*}{ Story version } & Baylor University & Algebra-based & Post-instruction & $\begin{array}{l}\text { Graded online } \\
\text { homework } \\
\text { assignment }\end{array}$ & $N=125$ & $90 \%$ \\
\hline & DePaul University & Algebra-based & Postinstruction & Graded in-class test & $N=47$ & $100 \%$ \\
\hline & $\begin{array}{l}\text { Penn State University- } \\
\text { Greater Allegheny }\end{array}$ & Calculus-based & Postinstruction & $\begin{array}{l}\text { Online homework } \\
\text { assignment, } \\
\text { participation points }\end{array}$ & $N=17$ & $57 \%$ \\
\hline Diagram version & Seattle Pacific University & Algebra-based & Postinstruction & $\begin{array}{l}\text { In-class written } \\
\text { assignment, extra } \\
\text { credit for completion }\end{array}$ & $N=52$ & $68 \%$ \\
\hline \multicolumn{7}{|l|}{$\begin{array}{l}\text { Box on a spring } \\
\text { question }\end{array}$} \\
\hline Story version & $\begin{array}{l}\text { Western Washington } \\
\text { University }\end{array}$ & Calculus-based & Pre-instruction & $\begin{array}{l}\text { Out-of-class pre-lab, } \\
\text { participation points }\end{array}$ & $N=229$ & $98 \%$ \\
\hline \multirow[t]{2}{*}{ Diagram version } & University of Maryland & $\begin{array}{l}\text { Physics for life } \\
\text { sciences }\end{array}$ & Postinstruction & $\begin{array}{l}\text { In-class written } \\
\text { assignment, } \\
\text { participation points }\end{array}$ & $N=278$ & $100 \%$ \\
\hline & Seattle Pacific University & Calculus-based & Postinstruction & $\begin{array}{l}\text { Written homework } \\
\text { assignment, } \\
\text { participation points }\end{array}$ & $N=55$ & $76 \%$ \\
\hline \multirow{2}{*}{$\begin{array}{l}\text { Bowling ball free } \\
\text { body diagram } \\
\text { question }\end{array}$} & DePaul University & Algebra-based & Postinstruction & Graded in-class quiz & $N=51$ & $100 \%$ \\
\hline & Seattle Pacific University & Algebra-based & Postinstruction & $\begin{array}{l}\text { In-class written } \\
\text { assignment, extra } \\
\text { credit for completion }\end{array}$ & $N=52$ & $68 \%$ \\
\hline \multirow[t]{2}{*}{$\begin{array}{l}\text { Sarah pushes a } \\
\text { box free body } \\
\text { diagram question }\end{array}$} & University of Maryland & $\begin{array}{l}\text { Physics for life } \\
\text { sciences }\end{array}$ & Postinstruction & $\begin{array}{l}\text { In-class written } \\
\text { assignment, } \\
\text { participation points }\end{array}$ & $N=278$ & $100 \%$ \\
\hline & Seattle Pacific University & Calculus-based & Postinstruction & $\begin{array}{l}\text { Written homework } \\
\text { assignment, } \\
\text { participation points }\end{array}$ & $N=55$ & $76 \%$ \\
\hline
\end{tabular}

\section{COMMON, PREVALENT CONCEPTUAL RESOURCES FOR UNDERSTANDING ENERGY}

In this section, we report those resources that emerged frequently, in multiple instructional contexts, and across questions-i.e., the common, prevalent conceptual resources that introductory physics students used when reasoning about energy. Because the majority of the students in our samples responded to our questions after physics instruction, we interpret these resources as those that may be elicited by instructors during or after physics instruction, as students are sense making or have sense made about formal energy ideas. However, as we will see, a number of these same resources emerged from student responses at Western Washington University, which represent pre-instructional ideas, so it is possible that many of these resources can be elicited and capitalized on at the beginning of formal university physics instruction. 
Generally, we report resources that came up for at least $20 \%$ of the students in one context and emerged at some other frequency in several more. To be clear, when we report percentages of student responses that drew on each resource, we do not mean to communicate that this is the percentage of students who have this resource in any stable sense of the word. Rather, the percentages reflect the fraction of student responses that we interpreted as opportunities for instructors to build on a given resource in a particular context.

As we will show, we found that students often

- accounted for energy transfers and transformations in a scenario,

- associated forms of energy with indicators or changes in energy with indicators of change,

- linked energy to forces or work,

- implicitly used the second law of thermodynamics to reason about thermal energy transfer or energy degradation, and

- represented energy quantitatively.

We unpack each of these resources and their manifestation in student responses in the following sections, and we discuss how we see each one as the "raw material" out of which more sophisticated and/or canonically correct ideas might be built. We frame these raw materials as "beginnings"-we do not expect these ideas to be fully developed or canonically correct, and, in fact, we will see that several are not, or are embedded in responses that are canonically incorrect. The promise of instruction that

capitalizes on student ideas lies in the interaction between students and instructors (or peers) who see these beginnings and build on or refine them-this vision is what we are trying to enhance in reporting and illustrating these resources.

\section{A. Students account for energy transfers and transformations in a scenario}

These resources refer to students' efforts to account for gains, losses, and changes in the forms of energy present in the scenarios in our questions. The two most common variations in this resource included (i) tracking energy as it moves through the system and (ii) accounting for the energy at the beginning and end of the scenario. Each of these variations represent an "in" to energy conservation: even if students did not explicitly acknowledge that the total amount of energy should be the same at the beginning and end of the scenario (unless work was done), beginning or end accounting can be a "way in" to thinking about whether energy was lost or gained, and if so, how. Likewise, describing the flow of energy through a sequence of objects and instants may be a first step to accounting for all of the energy transfers and transformations that occur during some process. By tracking the energy present at multiple instants, students are (perhaps implicitly) acknowledging that energy "moves" through different locations and manifestations, which is an important part of the conservation principle [107,113-115,129].
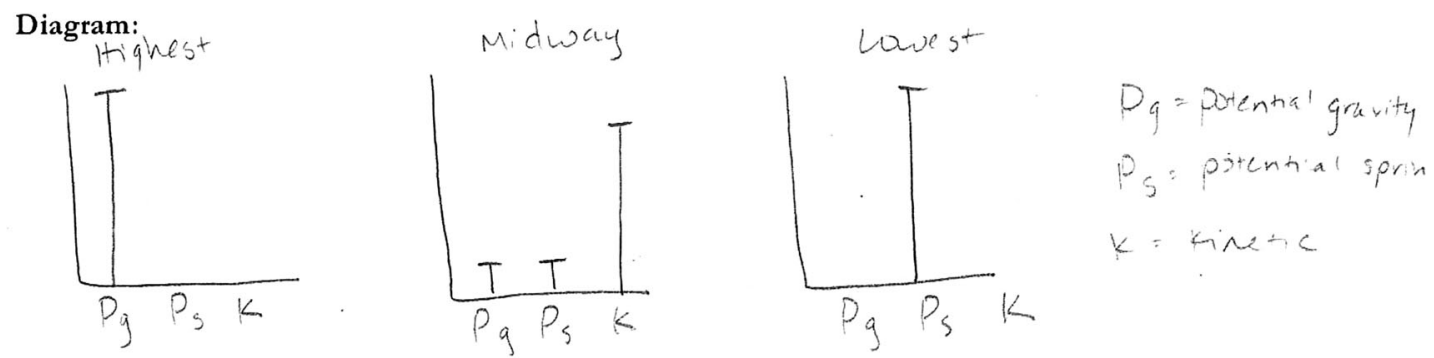

For each transfer and transformation that you indicate in your diagram:

a. Describe your evidence that the transfer or transformation has occurred.

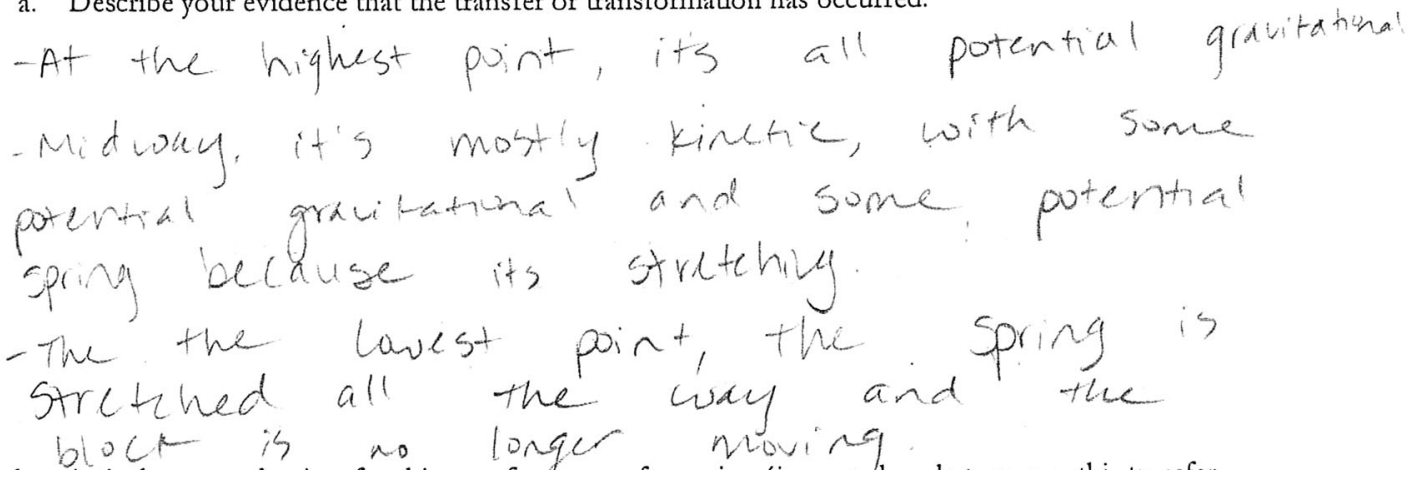

FIG. 7. Example student response for "students track energy as it moves through a system" (box on a spring question, Seattle Pacific University calculus-based physics). 
(b) In the space below, draw a diagram showing the energy :ransfers and transformationis within and/or among the objects in this scenario (specify what are the relevant objects in the scenario in your diagram)

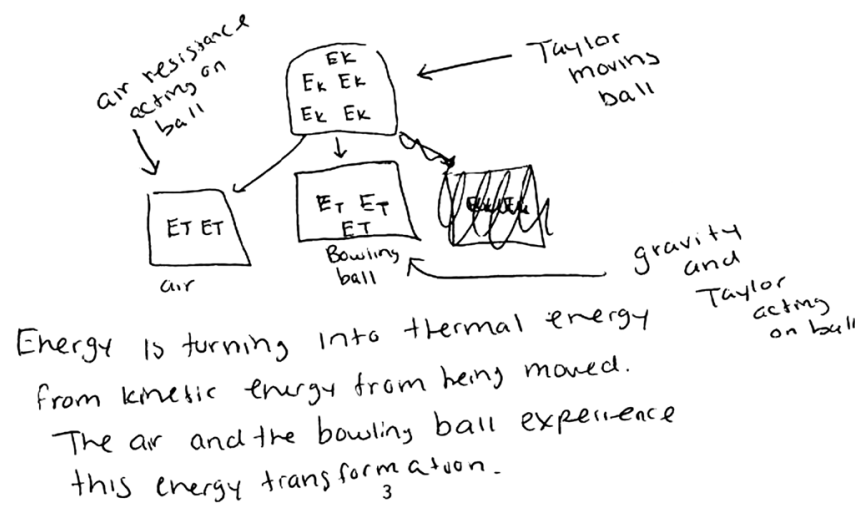

FIG. 8. Example student response for "students track energy as it moves through a system" (bowling ball free body diagram question, DePaul University).

\section{Variations in student use of resource}

Students track energy as it moves through a system.These student responses link a series of observable events with the energy involved, by either describing several sequential energy transfers and/or transformations or describing the forms and locations of the energy present at several instants in time. Figures 7 and 8 and the quote below illustrate this category:

"The energy that is initially in the cold pack is potential energy. This energy is converted to thermal energy when the chemicals are released. This energy now creates a loss of heat making the ice pack cold. When she places the ice pack on her ankle there is a transfer of thermal energy from the pack to her ankle. Total energy is always conserved but some energy is lost due to heat." (Emily question, Baylor University)

In each of these examples, students describe or depict (i) the energy at multiple instants in time or (ii) transfers and transformations across moments in time. The responses represented by the typed quote and by Fig. 8 talk about the conversion or transformation of energy from one form to another; the responses in Figs. 7 and 8 represent the fraction of the (constant) total amount of energy that is indicated by each form; and the response in Fig. 8 shows where the energy in the system is located at two different instants in time. These responses - and others given this code-may not represent complete or canonically correct descriptions of the energy in the system at any given moment (e.g., they may not describe every transfer or transformation of energy). However, in each of these responses we see students following energy through the scenario, which we see as a necessary first step to the conservation of energy.

Students account for the energy at the beginning and end of the scenario.-We gave the "beginning-end accounting" code to student responses that both (a) described the forms of energy present at the beginning of the scenario and then (b) described how those forms transferred to different locations or transformed into different forms by the end of the scenario. These responses may not have explicitly articulated that the amount of energy is the same at the beginning and the end, but language describing how one form of energy becomes another can provide an "in" for instructors to bring up energy conservation. While

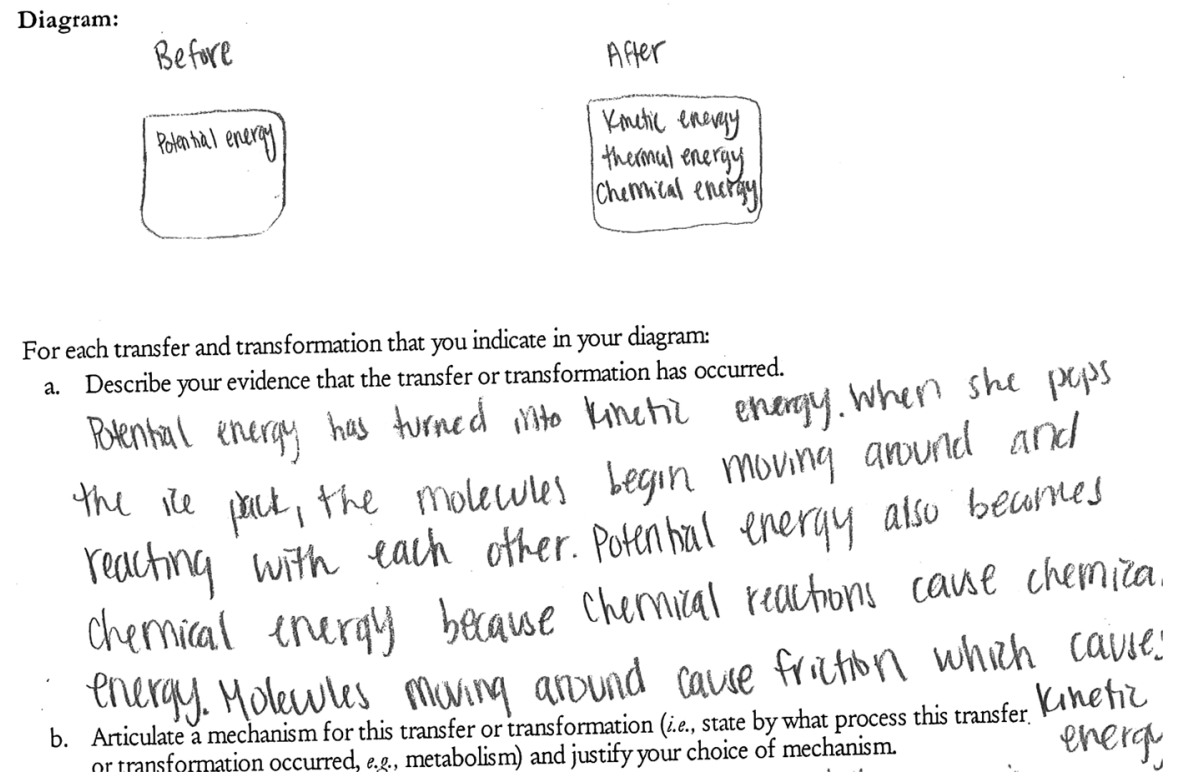

FIG. 9. Example student response for "students account for the energy at the beginning and end of the scenario" (Emily question, Seattle Pacific University algebra-based physics). 
b. In the space below, draw a diagram showing the energy transfers and transformations within and/or among the objects in this scenario (specify what are the relevant objects in the scenario in your diagram).

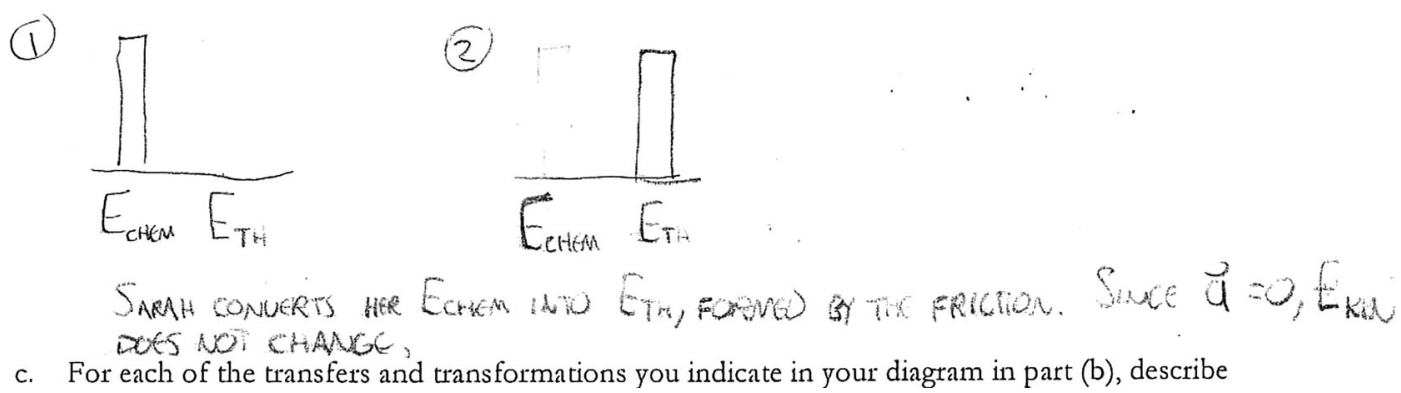

FIG. 10. Example student response for "students account for the energy at the beginning and end of the scenario" (Sarah pushes a box free body diagram question, Seattle Pacific University calculus-based physics).

students' responses rarely included quantitative information, they tended to indicate that the energy at the beginning of the scenario became the energy at the end of the scenario, suggesting that students may have been thinking of a constant amount of energy that is transferred or transformed. The examples in Figs. 9 and 10 and in the quote below illustrate this category:

"The net work done on an object is equal to the change in the object's kinetic energy. I would also like to think about how at the beginning, at the bottom of the stairs, the box has no gravitational potential energy. At the top of the stairs, the box will have a gravitational potential energy of the mass times gravity times the height. So we would need to know the mass of the box and its final height. With this in mind, I would say that the gravitational potential energy is how much energy David gave to the box as he carried them up the stairs." (David question, Baylor University)

In each of these sample responses, the student indicates either what kinds of energy were present at the beginning and end of the scenario (Figs. 9 and 10), or describes the change in a form of energy from the beginning to end of the scenario (typed response).

\section{Prevalence of resource}

Table IV lists the percentages of responses in each sample that reflected this resource. The first row depicts the percentages of responses that were coded with any resource that accounted for energy changes, including tracking and beginning-end accounting, as well as explicitly citing the conservation of energy principle or identifying a source of energy. The second and third rows list percentages for the two most common variations of the resource (tracking and beginning-end accounting).

As can be seen in the table, "energy accounting" resources came up in student responses from every university and in response to every question: $83 \%$ of student responses in one context (Emily question, DePaul University) - and more than $20 \%$ in many others-were coded with at least one energy accounting resource. We notice that these resources were less prevalent in responses to the David question, perhaps because this was the only question that did not explicitly ask students to describe energy transfers and transformations.

\section{Discussion and implications for instruction}

Much of the existing literature on student ideas about energy suggests that the concept of energy conservation is difficult for students. For example, several report that learners tend to think that energy is used up, rather than conserved $[107,110,118,124]$. Others report that students have trouble interpreting or applying the idea of conservation of energy [133] or that students do not use the concept of energy conservation to solve problems or analyze systems $[107,108,111]$. However, we find that the college introductory physics students in our study do account for energy transfers and transformations in a number of energy scenarios, which we consider to be consistent with-or at least the beginning of - the conservation of energy principle, even if students may not explicitly cite this principle or use canonically correct language. In this sense, we argue for a reframing of the finding that students often do not conserve energy; we consider their ideas productive beginnings, rather than problematic endpoints.

We propose that instructors can build on these energy accounting resources by encouraging students to account for energy transfers and transformations and/or apparent gains or losses in energy. This practice might be promoted by using energy tracking representations such as those described in the literature $[120,129,134,135]$, or simply by asking students to describe energy transfers and transformations as we did in our free body diagram and story questions. 


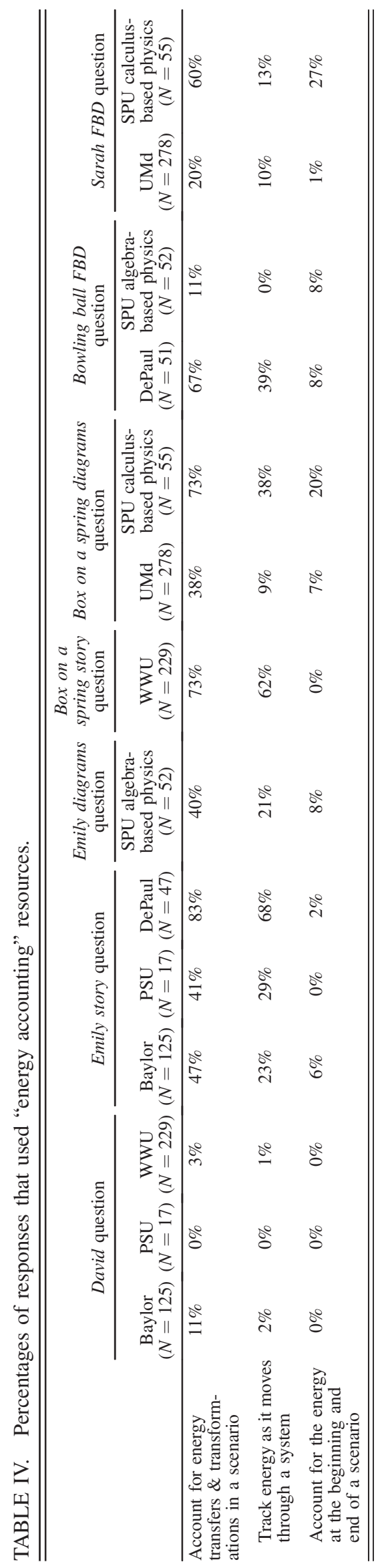

\section{B. Students associate (i) forms of energy with indicators and (ii) changes in energy with indicators of change}

\section{Description of resource}

This code was given whenever student responses linked physical indicators in the scenario (e.g., light, temperature, sound) to energy forms or changes in energy. For example,

“... David definitely gives the books energy because they change position." (David question, Baylor University)

"...if the box is moving it must have some amount of kinetic motion." (box on a spring question, Western Washington University)

"Chemical Potential [to] Thermal-popping the button caused the temperature to change. Thermal transferred to air-the ice pack got cold so thermal energy had to leave the system to decrease temperature." (Emily question, DePaul)

In these examples, students used observable evidencesuch as motion or a change in position or temperature- to justify their claims about the presence of or changes in energy throughout the system.

\section{Prevalence of resource}

Table V lists the percentages of student responses for each sample that reflected this resource. We see that this resource emerged in student responses to every question and from almost every sample; it was also reported in interviews and classroom dialogue among elementary and secondary students in Radoff et al. [105] and Harrer et al. [33]. As many as $73 \%$ of responses in our sample (box on a spring question, Seattle Pacific University calculusbased physics) associated forms with indicators and changes in energy with indicators of change. Again, here, this resource was less prevalent in response to the David question, perhaps because this question did not focus students' attention on evidence for energy transfers and transformations.

\section{Discussion and implications for instruction}

Associating forms with indicators and changes in energy with indicators of change can be productive in several ways. Indicators can link energy, an abstract concept, with students' concrete experiences and intuitions. Students who link forms and indicators make inferences based on what they have observed - an important scientific practice—and their responses reflect an appropriate understanding of the nature of energy. Further, identifying indicators of energy forms or changes can be the first step to tracking the flow of energy through a system. In these senses, we reframe the literature's characterization of "associating energy with [only] motion or other obvious activities" [101,106,107,117,118]; rather than 


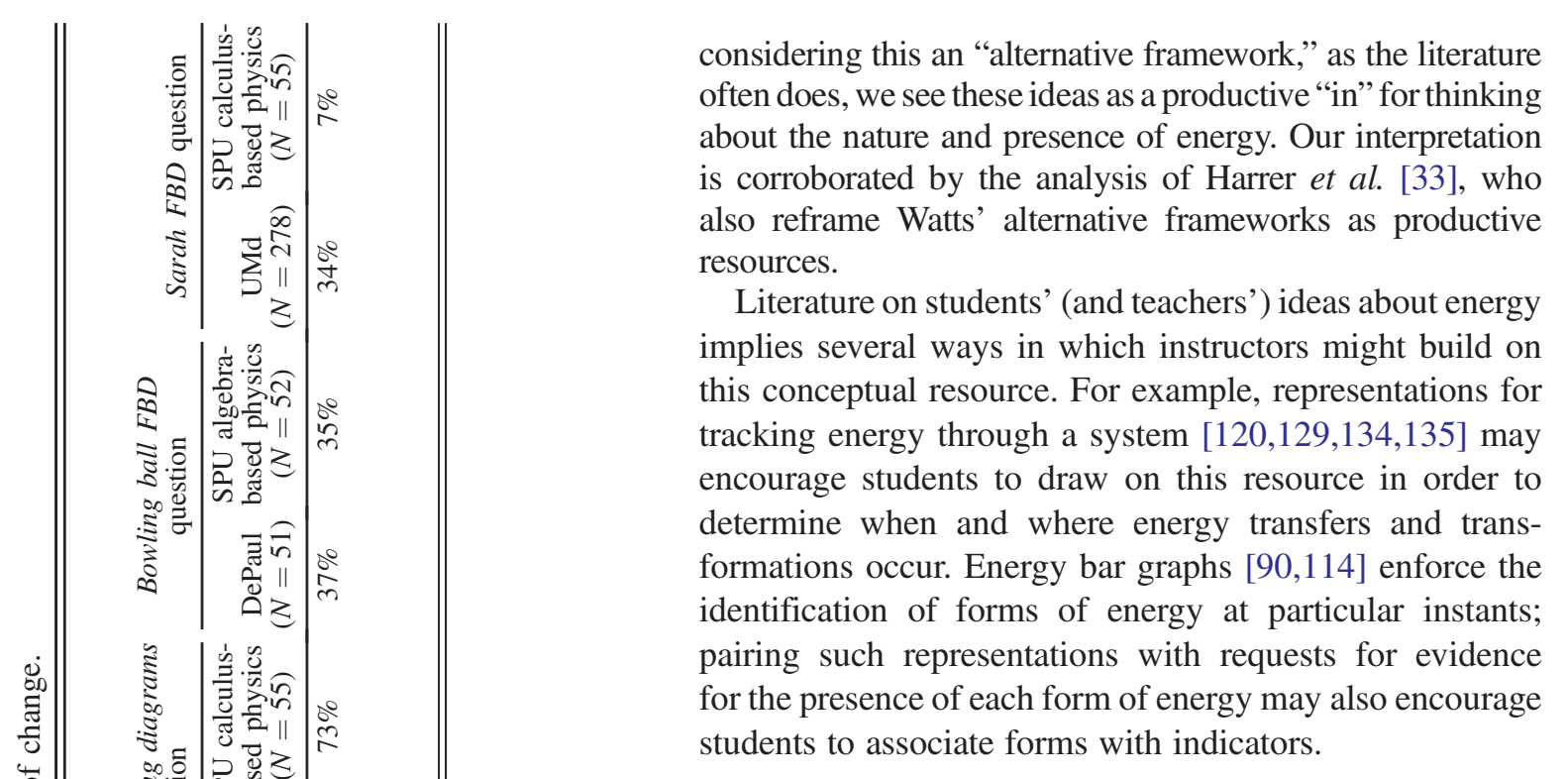

\section{Students relate energy to forces and/or work}

This code was generally given to student responses that reflected the beginnings of a conceptual link between energy and forces or work. This came up in a number of different ways: Some students directly associated forces with energy transfers and transformations. Others attributed the presence of specific energy forms to specific forces. Still others linked energy and work by defining the latter as a change in or transfer of energy; recognized that energy transfers at contact; or identified chemical energy as the starting place for doing work.

\section{Variations in student use of resource}

Students associate forces with energy transfers and transformations.-Several responses that received the "associating forces with energy transfers and/or transformations" code linked forces to energy transfers or transformations causally, specifically stating that a change in energy occurred because of the application of a force. For other responses that received this code, the association was less overt; e.g., students said that an energy transfer happened when a force was applied, rather than linking them causally. For example,

“...The mechanism for the transfer [of gravitational energy] relies on gravity's force on the box, displacing the spring and increasing the tension force that is stored within the spring" (box on a spring question, Seattle Pacific University calculus-based physics)

"Sarah put energy into pushing the box that transfers to kinetic energy...Sarah causes movement meaning potential energy is being transferred to kinetic energy... The force of Sarah on the box relates to the PE to KE transfer." (Sarah pushes a box free body diagram question, University of Maryland) 
"The force of gravity is related to the transfer of potential energy to kinetic energy." (bowling ball free body diagram question, DePaul)

Although not necessarily canonically correct, these sample responses do link forces with changes in energy. The first attributes the change in gravitational energy to the gravitational force that changes the spring's position (resulting in a transfer of energy to the spring); the second relates the force that Sarah exerts on the box to the transfer of energy from her to the box; and the third associates the gravitational force with a particular energy transformation. In each of these responses, we see opportunities for instructors to dig deeper into the relationship between forces and energy, and springboards from which students may build a robust understanding of various mechanisms of energy transfer.

Students associate forces with the presence of particular forms of energy.-Student responses that received this code linked the presence of (rather than a change in) a specific form of energy with a particular force that was being applied to the system. These responses used the force as an indicator of a particular kind of energy. However, this code differs from "associating forms with indicators" because the force is not an observable quantity (such as temperature or brightness) related to the object that "has" energy. For example:

"The force due to friction [caused by the bowling ball as a result of contact with the floor] is related to the heat (joules) given off (i.e., the work energy transforming into heat energy) as it moves across the floor." (bowling ball free body diagram question, DePaul)

"[There is] $E_{S P}$ [spring energy] because the spring is being stretched and $E_{T h}$ [thermal energy] because of the drag in the air." (box on a spring question, Seattle Pacific University calculus-based physics)

"...The force of friction relates directly to thermal E." (Sarah pushes a box free body diagram question, University of Maryland)

In each of these sample responses, we see students connecting a force that they know is being exerted and a type of energy that they either observe or infer: frictional forces and heat or thermal energy (all three responses), and spring forces and elastic potential energy (second). Ideas such as these could serve as "seeds" of more sophisticated ideas like associating forces with energy transfers or transformations.

Students define work as a change in or transfer of energy.-Responses that received this code related changes in energy or transfers of energy to work. Some also recognized that the work done on an object was related to the dot product of the force and the displacement of the object. For example:
"[To figure out the energy David gives to the books,] I would figure out the force exerted on the books by gravity and the force it takes to push the books the distance of the stairs in a frictionless environment then I would add the values together and convert newtons to joules." (David question, Western Washington University)

"[My evidence for the transfers and transformations of energy in my diagram are:] U_G: Gravitational potential decreases because the spring and the box are falling toward the floor...E_S: Spring energy increases as the spring and box fall because the spring is being stretched out...[The mechanisms for these transfers and transformations include:] As the box falls, it performs spring work on the spring, since the spring must stretch as the box falls to the ground...[and] the Earth does mechanical work on the box." (box on a spring question, Seattle Pacific University calculus-based physics)

"KE is transferred from Sarah to the box because work is being done on the box which is indicated by the box moving...The forces on the free body diagram show how the energy is being transferred. Sarah is putting force on the box (doing work) which transfers the KE from her body to the box in order to give the box some velocity." (Sarah pushes a box free body diagram question, University of Maryland)

In each of these examples, students say that work is either equal to the change in energy (e.g., first response) or is the mechanism for energy change (second and third responses).

Students recognize that energy transfers at contact.-We identified this resource in responses stating that energy transferred when two objects were in contact with one another. The examples below and in Fig. 11 illustrate this resource:

"[There is an increase in spring energy because] the spring is being pulled out of equilibrium, so it gains

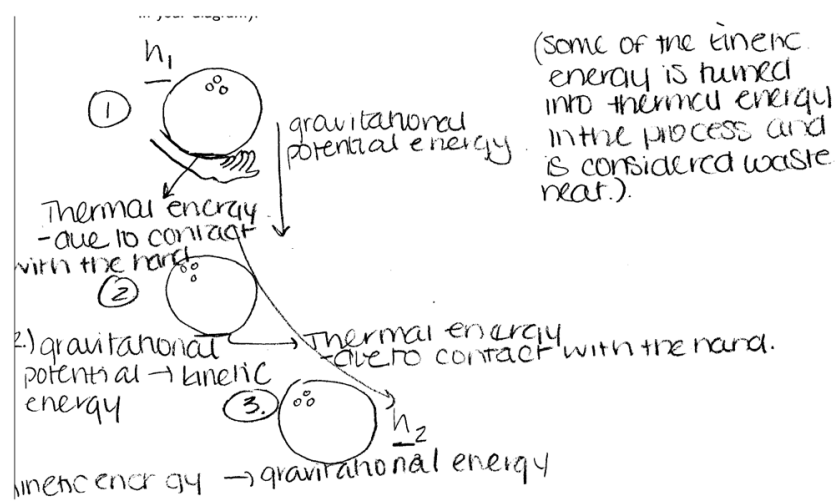

FIG. 11. Example student response for "students recognize that energy transfers at contact" (bowling ball free body diagram question, DePaul). 
energy...[The mechanism that caused this increase is the] contact force, because the block is pulling it" (box on a spring question, Seattle Pacific University calculus-based physics)

"When she places the ice pack on her ankle there is a transfer of thermal energy from the pack to her ankle....it transferred the heat via touch and the heat diffused between the two membranes." (Emily question, Baylor University)

In responses such as these, we see students thinking about how energy transfers between objects. Though there is more to the mechanism of energy transfer at contact than simply that the objects are touching, we see these ideas as starting places for thinking about the first law of thermodynamics-in particular, macroscopic energy transfers through work or microscopic transfers of kinetic energy (i.e., heat).

Students recognize that work done by humans is fueled by a chemical energy source.-Responses received this code when they indicated that chemical energy is a source for the work done or forces exerted by humans. For example:

"The body uses chemical energy which produces muscle motion and heat. The force of the person pushing against the box causes it to move... The chemical potential and the spring potential both cause the extension (arm and spring respectively) which in turn applies a force on the box." (Sarah pushes a box free body diagram question, Seattle Pacific University calculus-based physics)

"He is giving the books potential gravity energy by converting his food energy into movement... You would need to know the calories he used to move up the stairs and hold the box." (David question, Western Washington University)

In these examples, students say that chemical energy makes it possible for muscles to move and thus for a person to push or lift a box. In these cases and others, students treat chemical energy as the starting place for the work humans do, implicitly (or explicitly) invoking the principle of conservation of energy.

\section{Prevalence of resource}

Table VI depicts the percentages of student responses for each sample that reflected each variation in this resource. We see from Table VI that student responses that related energy to forces or work were common in the box on a spring, bowling ball free body diagram, and Sarah free body diagram questions. The resource emerged in student responses to every question, albeit not at every school. Students most frequently associated forces with energy transfers and transformations when asked to list

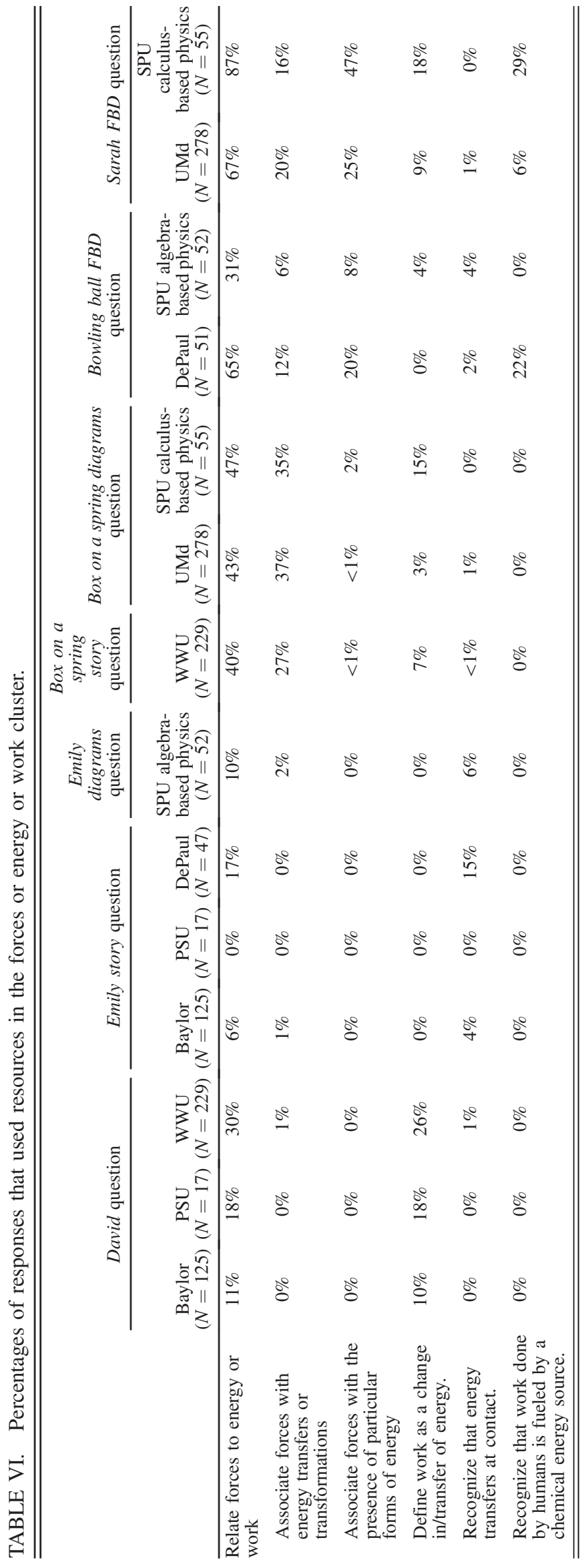


mechanisms for the latter, and students most frequently associated forces with specific types of energy in cases where friction and air resistance were salient.

\section{Discussion and implications for instruction}

There are many ways in which these ideas could be productive. Most directly, students who associate forces with energy transfers or transformations and those who associate work with changes in energy recognize (implicitly or explicitly) that forces or work are mechanisms for energy transfer and transformation. Associating forces with particular forms of energy can be thought of as a "beginning" of associating forces with energy transfers or transformations or associating forms with indicators. The pursuit of causal mechanistic accounts is central to scientific analysis $[32,46,48,74]$, and "richly scientific depictions of the energy dynamics of a system or scenario include mechanisms for energy transfer and transformation" [98].

Associating forces or work with energy transfer and transformation may be a "way in" to energy conservation. For example, defining work as a change in energy may be a first step in understanding the movement of energy from one location to another. Likewise, treating chemical energy as a starting place for doing work recognizes that energy had to "come from" somewhere. Associating forces or work with energy transfers may also be a starting place for thinking about situations in which the total energy of a system is not constant.

Some of these same resources may also be "ways in" to more quantitative representations of the conservation of energy, such as the work-energy theorem or the first law of thermodynamics. Whereas other researchers report difficulties that students have in applying the work-energy theorem to physical situations $[127,133]$ and in relating work to a change in energy [111], we find that students in our sample use these ideas frequently and fluidly. Students in our sample also recognize other definitions of work, such as the dependency of work on force and displacement. Further, students who state that energy transfers at contact are implicitly invoking the first law of thermodynamics, in which energy transfers through heating (macroscopic conduction or microscopic collisions) and working (macroscopic contact).

Instructors might build on these ideas by attending to opportunities to introduce energy conservation, the workenergy theorem, the second law of thermodynamics, or mechanistic accounts of energy as these ideas emerge in the natural flow of classroom activity. Instructors may also elicit these ideas by asking students to make explicit connections between force and energy representations, or by introducing representations that enforce the identification of mechanisms for energy transfers and transformations, such as Energy Tracking Representations [120,134,135].

\section{Students implicitly use the second law of thermodynamics}

Student responses often reflected the implicit use of the second law of thermodynamics. This took two primary forms: student ideas (i) about energy loss, degradation, and spreading, or (ii) about the flow of thermal energy from hot to cold objects.

\section{Variations in student use of resource}

Students recognize that energy can be lost as thermal energy or sound or that energy spreads.-Students often accounted for energy losses by describing transformation into and transfer of thermal energy. We gave the "energy degradation" code to responses that stated that thermal energy is lost, released, dissipated, dispersed, or other similar language; we did not give this code to responses that described transformations into thermal energy without indicating that energy was "lost." Examples of student responses that received the "degradation" code include:

"The one thing I do know about energy is that energy is conserved. And whatever energy that is put into the system (the book and David) can never be lost but given off as thermal energy or sound..." (David question, Baylor University)

"...chemical energy is changed to kinetic energy in the bowling ball. As the ball is being lowered, some of that kinetic energy leaves the ball and is lost to the air as thermal energy." (bowling ball free body diagram question, DePaul)

"Sarah uses chemical energy to push the box and give it $K E$, which is lost to the molecules in the floor as thermal energy." (Sarah pushes a box free body diagram question, University of Maryland)

In each of these sample responses, students treat the scenarios in question as dissipative, often connecting apparent energy losses to transformations of energy into thermal or sound. In the first response, the student clarifies that the energy of the system stays the same unless there is some dissipative process at work; and in the second and third responses, the student acknowledges the dissipative forces at play-including air resistance and friction-in the particular scenarios they have been asked to analyze.

Students acknowledge that thermal energy flows from higher to lower concentrations until thermal equilibrium is reached.-We assigned this code to responses that showed students specifically thinking about the flow of thermal energy from areas of high temperature to areas of low temperature. This included responses that (a) described thermal energy or heat flowing from warmer objects to colder objects, (b) implied a sense of "wanting to reach equilibrium," either saying that the energy flow between objects stops when they are the same temperature or saying 


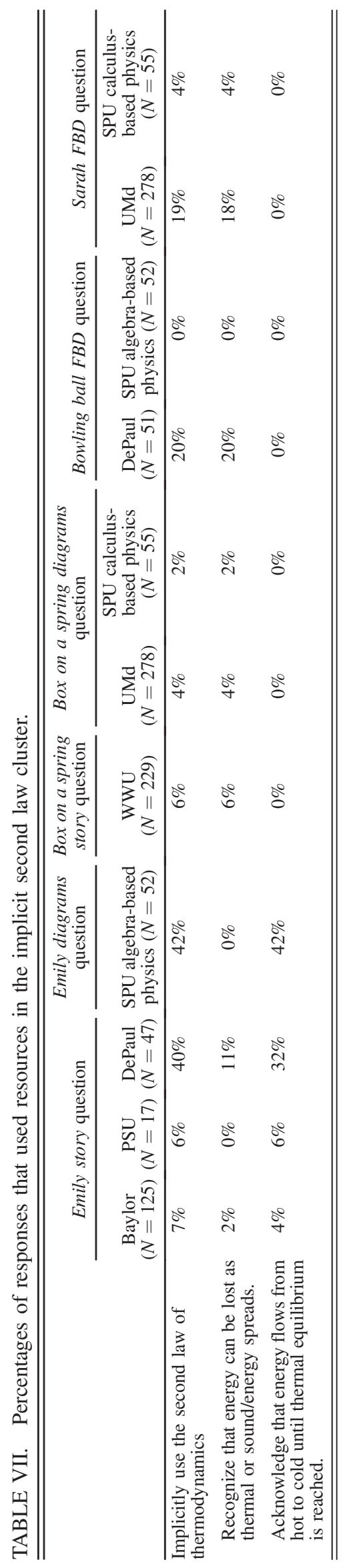

that energy will move because the system is not at equilibrium, or (c) explained that temperature differences cause conduction. For example:

"The transfer will surely [occur] because the second law of thermodynamics will be applied. The heat will flow from swollen ankle (body temperature) to the ice pack (temperature close to $0 \mathrm{C}$ )." (Emily question, DePaul)

"Heat transfers to colder objects. Since the ice pack is colder than Emily's ankle, the heat will travel towards the bag until it reaches equilibrium." (Emily question, Seattle Pacific University algebra-based physics)

"Heat is transferred from Sarah to the box because she is touching it and she is most likely warmer than the box." (Sarah pushes a box free body diagram question, University of Maryland)

"Initially, the energy is dormant. I'm assuming this would be potential energy. After popping the button, the potential energy transforms into a chemical energy making the cold pack change temperature. Once Emily places the cold pack on her ankle, higher energy will move to lower energy. Thus, the ankle will lose energy and the cold pack will gain energy." (Emily question, Penn State Greater Allegheny)

In these examples, students show that they understand that the flow of energy is directional, and all of them attribute directionality to differences in temperature or energy concentration, both important aspects of the second law of thermodynamics. Some responses (e.g., the second response above) used the idea of equilibrium to indicate that there is a point when the energy will stop flowing.

\section{Prevalence of resource}

Table VII lists the percentages of responses that used one of the two variations described above. Responses from every university for almost all questions (except the David

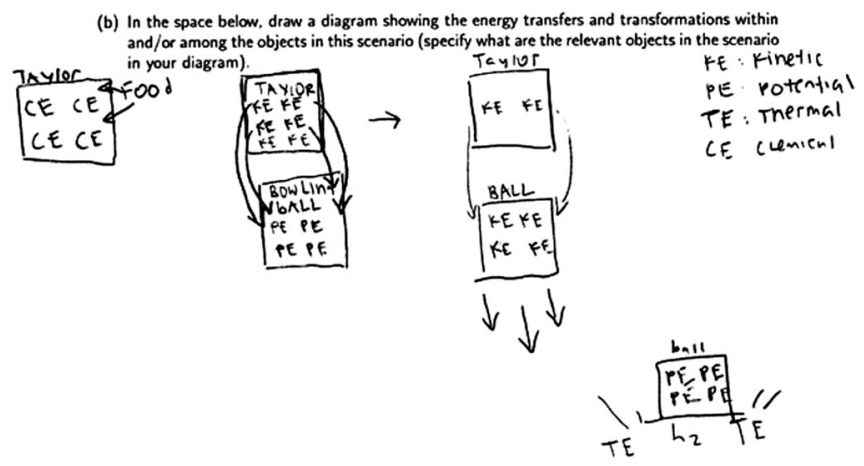

FIG. 12. Example student response for "students quantify relative amounts of energy" (bowling ball free body diagram question, DePaul). 


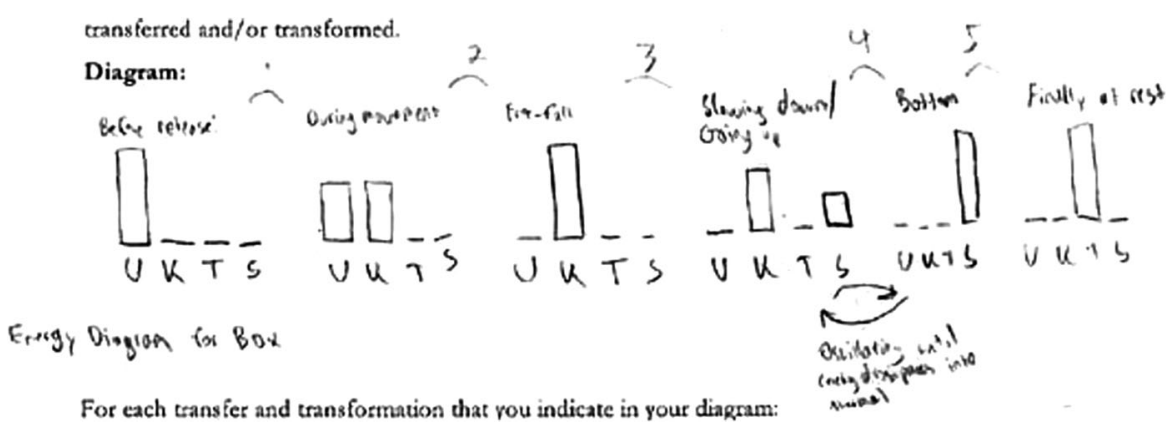

FIG. 13. Example student response for "students quantify relative amounts of energy" (box on a spring question, Seattle Pacific University calculus-based physics).

question) received codes in the "implicit second law" cluster; resources of this kind were also prevalent in dialogue among teachers, reported by Daane et al. [1]. As many as $20 \%$ of the responses in our sample (bowling ball free body diagram question, DePaul) reflect the "energy degradation" code, even for those questions that did not specifically mention thermal energy. Ideas about heat flowing from hot to cold or reaching thermal equilibrium primarily emerged in the Emily questions, where as many as $42 \%$ of responses received that code.

\section{Discussion and implications for instruction}

Some have found that students misunderstand or overlook the second law of thermodynamics [108,126]. However, we find that students often use ideas or principles that connect to or are implications of the second law of thermodynamics. For example, the idea that thermal energy spreads or moves towards equilibrium is a consequence of the second law: because entropy tends to increase, energy moves from areas of higher concentration to areas of lower concentration until equilibrium is reached.

To capitalize on these ideas as a resource for understanding the second law of thermodynamics, instructors might encourage students to extend this thinking to other scenarios in which energy seems to be lost. Instructors can support students in refining these ideas toward a more sophisticated understanding of the second law by asking students to explain why thermal energy is lost to the environment, why thermal energy moves from warmer to cooler objects, or why a system "wants to be in equilibrium."

Further, some literature suggests that ideas about thermal energy loss and spreading can be a resource for understanding the canonical concept of energy conservation. Understanding that energy in a system can be "lost" to the surroundings and that thermal energy spreads can serve as a bridge between a popular understanding of energy, where energy is used up, and a scientific understanding of energy in which energy is always conserved $[1,104,124]$. In fact, Solomon [112] recommends beginning the topic of conservation with degradation in order to avoid implying that conservation means that energy cannot leave a system.

\section{E. Students quantitatively represent energy scenarios}

Although our questions did not include any numerical values, some students used equations to reason about the energy present in a particular scenario. When responses (i) identified the dependency of a particular form of energy on particular variables or (ii) compared the relative amounts of energy in two different instants, we gave them this code.

\section{Variations in student use of resource}

Students identify the dependency of particular forms on particular variables.-Responses received this code when they identified the dependency of a particular form of energy on particular variables. ${ }^{3}$ For example, students related gravitational potential energy to mass, acceleration due to gravity, and height; kinetic energy to mass and speed; and spring potential energy to the spring constant and displacement of the spring. Examples of student responses that were coded this way include:

" $P E_{\text {_gravity }}=m * g * h$, so change in $P E_{\text {grav-box }}$ would be dependent on change in $h$. Since the mass of the box and its acceleration due to gravity is constant, a shorter distance to the ground would mean less PE." (box on a spring question, Western Washington University)

"To find the energy David gives the books, you would need to know the mass of the books, the initial and final velocity of the books, and the height the books were carried. The amount of energy that the books have at the bottom of the stairs is equal to the amount of energy that the books have at the top of the stairs, so using the equations $m g h_{1}+1 / 2 m v_{1}^{2}=m g h_{2}+1 / 2 m v_{2}^{2}$. So total energy does not change throughout the situation, but there could be a change in potential and kinetic energy

\footnotetext{
${ }^{3}$ Originally, we also included instances in which students identified the dependency of work on force and displacement in this code. However, we found upon careful look that most students were doing so in the service of relating work to changes in energy. Thus, we moved "identifying the dependency of work on force and distance" to the forces, energy, and work cluster (Sec. IV C).
} 


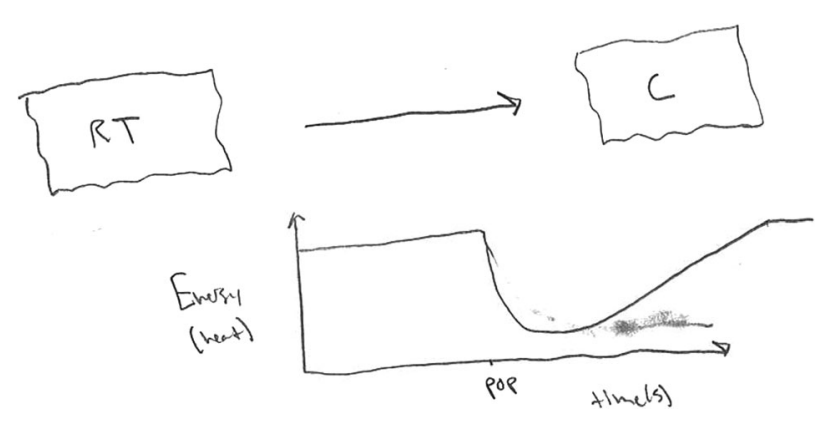

FIG. 14. Example student response for "students quantify relative amounts of energy" (Emily question, Seattle Pacific University algebra-based physics).

depending on the specific variables." (David question, Baylor University)

"If the velocity is constant, the KE will not change because $K E=1 / 2 m v^{2}$." (Sarah pushes a box free body diagram question, University of Maryland)

In these examples, students recognize that the total amount of energy (second response) - or the amount of a particular form of energy (first and third responses) - depends on the values for particular indicators. They use the relative quantities of these indicators to interpret the scenario, especially in situations in which the amount of a particular form of energy doesn't change (e.g., first and third responses).

Students quantify relative amounts of energy.-We gave this code to student responses that compared the relative amounts of energy from one instant to another or compared the amounts of different types of energy in single instants. Some responses kept the total amount of energy constant, while others focused on how one type of energy changed through the scenario. Almost all instances in which students used diagrammatic representations of energy received this code, as illustrated by the examples in Figs. 12-14.

In representing energy as units (Fig. 12), as bars that represent relative values (Fig. 13), or as a point on a line (Fig. 14), these example responses indicate at least the beginning stages of thinking about energy as something that can be described as a numerical quantity. Such diagrams also show that students are thinking about changes in the total quantity of energy in the systemor changes in the relative quantities of different forms of energy —as the scenario evolves.

\section{Prevalence of resource}

Table VIII lists the percentages of student responses for each sample that reflected this resource. Students quantified energy in one way or another for every question we asked in this study. This resource was most prevalent in the David question, where between $1 / 4$ and over $1 / 2$ of students'

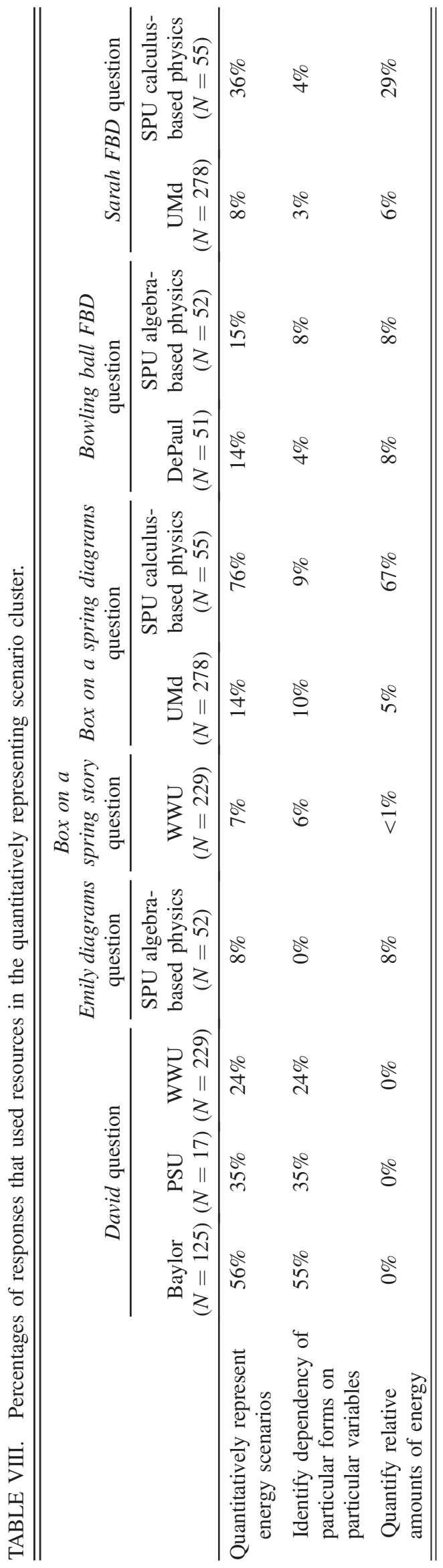


responses identified the dependency of particular forms of energy on specific variables.

\section{Discussion and implications for instruction}

In these responses, we see instances in which students are identifying the appropriate indicators for particular forms of energy, such as movement or velocity for kinetic energy and height for gravitational energy. Similar to associating forms with indicators and changes in energy with indicators of change, students recognize that energy is tied to observable quantities, such that all of the affordances we lay out in Sec. IV B 3 also apply here. Further, students in this category go beyond qualitatively associating forms with indicators; they also recognize that more indicator means more energy. Some researchers report that students associate energy only with moving or living things $[101,106,107,117,118]$; however, in our study we find that students associate energy with not just movement or life but also mass, height, acceleration due to gravity, the spring constant, and displacement of springs.

Students who use these resources are on their way to (or are already) translating a physical scenario into a set of equations that would allow them to make predictions about the behavior of a system, an important scientific practice. Instructors might build on these resources in the ways we describe in Sec. IV B 3, and they may press students to extend their use of some of those more qualitative energy representations (e.g., Energy Bar Charts) to depict relative quantities of energy.

\section{LIMITATIONS}

The resources we report in the previous section represent common, prevalent patterns in student responses; each one is reflected in at least $20 \%$ of the responses in a single context (i.e., a particular question at a single school) and some other frequency in multiple others. Although we expect that the question matters-and we see that different questions elicit individual resources at different frequency-we believe that these resources can be elicited in multiple contexts, such that an instructor can expect to see them emerge at some appreciable frequency in an "average" introductory physics course.

However, we acknowledge that there are a number of limitations to our analysis. In particular, the generalizability of our study is limited by our inability to determine the representativeness of our sample. However, this concern is mitigated by (i) the recurrence of our results across courses and question contexts, and (ii) our sampling method, which ensured that the majority of the students in each course answered our questions. Further, and perhaps most importantly, our primary aim is to foster an awareness of the resources that students may bring to their thinking about energy-we mean to offer example resources and to show that there are many opportunities to take up these example resources in student thinking about energy. It is not our intent to prove that these are the resources that will come up in every classroom.

Though we have provided general suggestions for building on the resources we identified, we expect that the specific instantiations of these resources will be idiosyncratic, such that it is difficult to provide specific guidance for responding to a particular resource in a given moment. We consider this both a limitation and an asset. It may limit the usefulness of our work for instructors who want this kind of guidance, but it recognizes the crucial role of context in instructor decision-making: we want instructors to make decisions that are appropriate for their local contexts; we would not wish to provide prescriptive guidance to instructors in this way. Case studies on classrooms in which the teacher attends and responds to the "seeds of science" in student thinking $[31,39,44,46,75,136-138]$ can supplement our work by providing detailed accounts of how teachers might take up and pursue student ideas in the natural flow of classroom activity.

Like any research that draws on written responses, we are limited to making claims based on the information that students provide in their responses. We are unable to ask students to clarify or elaborate on their ideas, and so our coding necessarily reflects our best efforts to infer what individual students mean. We made efforts to mitigate this limitation by creating an emergent coding scheme, based on student responses, rather than imposing an external scheme that reflects what we expected or wanted to see. Our coding method also required that the first two authors independently agree on each code a response received, reducing the subjectivity of our interpretations [78,139].

We acknowledge that we do not show that these ideas are productive, in the sense that they will necessarily lead to a more sophisticated understanding of energy, even with instructional support. This is beyond the scope of this exploratory work. However, the breadth of literature about instruction that attends to and builds on student thinking $[31,32,39,44,46,140]$ supports our sense that these ideas can be productive, with appropriate attention and support, as do case studies $[34,98]$ that describe the evolution of ideas commonly thought of as misconceptions or misontologies into sophisticated understandings of physics.

\section{DISCUSSION}

This study seeks to contribute to university physics instructors' pedagogical content knowledge and to their buy-in to the resources theory of knowledge by answering the question: What are some of the recurrent, prevalent conceptual resources used by university physics students when reasoning about energy? In our analysis of more than 800 student responses from six different US universities, we found that students often 
- accounted for energy transfers and transformations in a scenario,

- associated (i) forms of energy with indicators and (ii) changes in energy with indicators of change,

- related energy to forces and work,

- used ideas consistent with the second law of thermodynamics, and

- quantified the energy in specific scenarios.

The prevalence and commonality of these resources across contexts leads us to believe that these same ideas may come up in many instructional contexts, and thus that instructors may expect to have opportunities to capitalize on them.

Although we expect these resources to come up in an "average" instructional context, we do not mean to suggest that instructors use our categories to "bin" student ideas in the moment. Rather, we mean to encourage instructors to identify when students are using productive ideas, generally speaking, and to build on them; we suggest that our categories might serve as a springboard that can evolve on the basis of the particulars of a given instructional context. We resonate with the following quote from Donmoyer [77]:

"To be sure, research with large samples can provide clinicians with some idea of a certain strategy's probability for success-it can make teachers and researchers more informed gamblers, in other words-but even this advantage has a downside. Researchers' ideal types can easily become stereotypes..., and stereotypes, when applied to individuals, can easily become self-fulfilling prophecies... For example, findings that poor children will probably have reading difficulties may cause teachers and administrators to behave in ways that will actually create reading difficulties for particular poor children (Heath, 1982). Thus, for practitioners concerned with individuals, not aggregates, research can never be generalizable in the sense suggested by Thorndike. Research can only function as a heuristic; it can suggest possibilities but never dictate action."

Further, we found that students drew on many of these resources in a single response to a single question: most student responses received several different codes. For this reason, it is likely that there will be more opportunities for instructors to take up students' ideas than is logistically possible; we suggest that instructors use their professional expertise to determine which student ideas to pursue.

We saw in many cases that these resources were not canonically correct, or were embedded in student responses that were canonically incorrect. However, in identifying resources, we do not expect students' ideas to be canonically correct; we expect their ideas to contain "seeds" that instructors can build on to support students in developing a more sophisticated understanding of energy. While some of these resources are further from their fully formed canonical counterpart than others, we see all of them as "ways in" for instructors to develop their students' ideas. In fact, some of the resources that we found have been classified as misconceptions; we reframe these as possible beginnings.

Our goal in doing this work has been less theoretical, and more about potential instructional impact. However, we do feel that our work contributes to theory in an important way. In particular, resources researchers have been reticent to conduct large- $N$ studies or to make claims about the reproducibility of resources, in part because of the nature of the cognitive structure of resources and in part to avoid encouraging instructors to "bin" students. Our finding that specific resources recur across instructional contexts is certainly not precluded by resources theory; it is completely plausible that a single resource or network of resources may be activated in multiple contexts $[21,26,130]$. Our demonstration that this is not only plausible but does happen-and at relatively coarse grain sizes-offers a methodological bridge between misconceptions and resources research. We can conduct large- $N$ research to understand the common, prevalent resources students use and remain authentically committed to the ways in which we want to impact instruction (i.e., in an awareness or attention kind of way), as we have done here. Which brings us to our next point: while our study has identified some of the conceptual resources about energy that students may use, it is certainly not a comprehensive list. We encourage other researchers to conduct similar research in other domains, to expand instructors' repertoires beyond the context of energy.

Finally, we would like to extend our work to include preinstructional ideas about energy and other domains. As we say earlier, the majority of our data came from postinstructional contexts. This choice was pragmatic: many of the instructors who participated in our study were reluctant to ask students to respond to questions about energy before it was discussed in their courses. Other analyses suggest that the timing of conceptual questions does not affect student performance [141]; however, this may not be true for resources-oriented work, especially given our assumption that the context will affect which resources are activated.

\section{ACKNOWLEDGMENTS}

This material is based upon work supported by National Science Foundation Grant No. 122732. We are indebted to Daniel Bolton, Andrew Boudreaux, Benjamin W. Dreyfus, Mary Bridget Kustusch, Matt Lautenschlager, John Lindberg, Beth A. Lindsey, Vashti Sawtelle, Eleanor C. Sayre, and Lane Seeley for collecting data in their introductory physics courses; we could not have done this work without you. We are likewise grateful to Joel Corbo, who supported us in recruiting interview participants at the University of Colorado-Boulder. We also gratefully acknowledge the thoughtful feedback offered by members of the PER@SPU research team, including Abigail R. Daane, Lezlie S. DeWater, Sarah B. McKagan, Rachel E. Scherr, Lane Seeley, and Stamatis Vokos; by two 
anonymous reviewers; and by Benjamin W. Dreyfus and Mary Bridget Kustusch.

\section{APPENDIX: SAMPLE SOLUTIONS TO WRITTEN QUESTIONS}

Here we present a set of possible solutions to the David walks up stairs, Emily sprains her ankle, box on a spring, bowling ball free body diagram, and Sarah pushes a box free body diagram questions. To be clear, these questions were designed to have multiple possible "correct" answers and to draw on students' everyday experiences, so we do not consider our answers to be the only or even the best possible solutions. These are intended as a starting place for readers who are interested in our ways of understanding energy, forces, and work as they relate to these questions.

Possible solution to the David walks up stairs question:

If we assume that the books start and end at rest $(\Delta K E=0)$ and that the change in thermal energy of the books (due to heating from David or friction from the air) is negligible, then the gravitational potential energy of the books is the only form of energy that changes as David carries them up the stairs. We know that the gravitational potential energy of the books ${ }^{4}$ at any point is equal to the product of their mass, the acceleration due to gravity, and the height of the books, so $\Delta E=\triangle G P E=\Delta(\mathrm{mgh})$. Since the only one of these quantities that changes in this scenario is the height, then $\Delta E=\operatorname{mg} \Delta \mathrm{h}$, and we would need to know the mass of the books and the change in their height to figure out how much energy David gave them.

Possible solution to the Emily sprains her ankle question:

Essay (story version): When the button is popped, the chemicals that were in the button mix with the chemicals in the ice pack, and this initiates a chemical reaction. During the chemical reaction, thermal energy in the cold pack transforms into chemical energy in the cold pack, and the cold pack gets colder $(T \rightarrow C)$. When Emily places the cold pack on her ankle, thermal energy transfers from Emily's ankle to the cold pack; this thermal energy may also be transformed into chemical energy as the chemical reaction continues $(T \rightarrow T \rightarrow C$ ). (Some thermal energy also transfers from the air to the cold pack and from Emily's ankle to the air, but these are less central to this story.)

Diagram (diagram version): In Fig. 15, boxes represent objects, letters represent units of energy ( $T$ indicates thermal energy and $C$ indicates chemical energy), and arrows represent energy transfers or transformations.

\footnotetext{
${ }^{4}$ Throughout these solutions, we refer to the gravitational energy "of the box" or "in the spring," though we acknowledge that the gravitational energy is actually in the box-Earth or springEarth system. We explain these simplifying assumptions in more detail elsewhere. (See Ref. [135].)
}

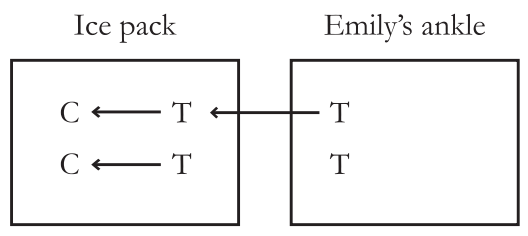

FIG. 15. Diagram depicting energy transfers and transformations in the Emily sprains her ankle question.

Evidence that each transfer or transformation has occurred:

- Evidence for the transformation of thermal energy to chemical energy in cold pack: Cold pack gets colder as the reaction proceeds, and the cold pack is not in contact with another object at a lower temperature.

- Evidence for transfer of thermal energy from Emily's foot to ice pack: Emily's foot gets colder and the ice pack gets warmer.

\section{Mechanism for each transfer or transformation:}

- Transformation of thermal energy to chemical energy in cold pack: Endothermic chemical reaction, because an endothermic chemical reaction "uses" energy, and I know the thermal energy in the ice pack has to go somewhere.

- Transfer of thermal energy between objects: Conduction, because conduction happens when two objects at different temperatures are in contact.

Possible solution to the box on a spring question:

Essay (story question): Assume that the box is released at rest from its equilibrium point (i.e., the point at which the spring is neither stretched nor compressed), such that the box and the spring start with no kinetic or elastic potential energy. If we ignore thermal processes, we can also ignore any thermal energy present in the box or spring.

Since the box and the center of mass of the spring start at some height greater than zero, they both begin with some gravitational potential energy. As the box and the spring fall, they move, transforming their gravitational potential energy into kinetic energy. The movement of the spring stretches it, transforming its kinetic energy into elastic potential energy. As the box moves and the spring stretches, the spring exerts a force on the box opposite its direction of
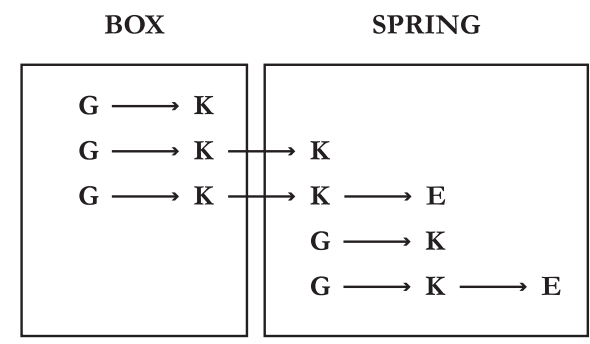

FIG. 16. Diagram depicting energy transfers and transformations in the box on a spring question. 


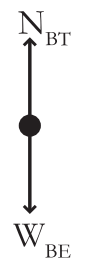

FIG. 17. Free body diagram for the bowling ball in the bowling ball free body diagram question.

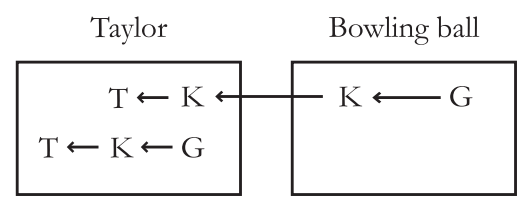

FIG. 18. Diagram depicting energy transfers and transformations in the bowling ball free body diagram question.

motion, so the spring does negative work on the box; thus, the box transfers kinetic energy to the spring.

Diagram (diagram question): In Fig. 16, boxes represent objects, letters represent units of energy ( $G$ indicates gravitational potential energy, $K$ indicates kinetic energy, and $E$ indicates elastic potential energy), and arrows represent energy transfers or transformations.

Evidence that each transfer or transformation has occurred:

- Evidence for the transformation of gravitational to kinetic energy in the box and spring: The box and the spring change height via movement. The box and spring speed up (increase their $K E$ ) as they fall (decrease their GPE).

- Evidence for the transfer of kinetic energy from the box to the spring: The box does work on the spring to stretch it (i.e., move its center of mass).

- Evidence for the transformation of kinetic to elastic potential energy in the spring: The spring stretches because it is moving.

Mechanism for each transfer or transformation:

- Transformation of gravitational to kinetic energy in the box and spring: Falling.

- Transfer of kinetic energy from the box to the spring: Mechanical work.

- Transformation of kinetic to elastic potential energy in the spring: Stretching.

For justifications of these mechanisms, see my evidence that each transfer or transformation has occurred.

Possible solution to the bowling ball free body diagram question:

Free body diagram for bowling ball as it is being lowered: Taylor is the only object in contact with the

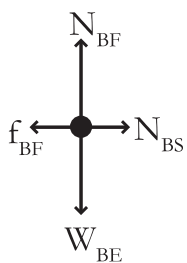

FIG. 19. Free body diagram for the box in the Sarah pushes a box free body diagram question.

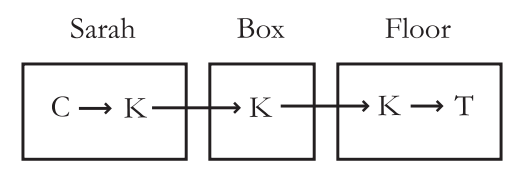

FIG. 20. Diagram depicting energy transfers and transformations in the Sarah pushes a box free body diagram question.

bowling ball, and the only noncontact force on the ball is the weight force (the ball is on Earth, is not magnetic, and is not charged nor experiencing electrostatic attraction). As illustrated by Fig. 17, the magnitude of the weight force $\left(W_{B E}\right)$ is equal to the magnitude of the normal force exerted by Taylor $\left(N_{B T}\right)$ by Newton's second law: the acceleration of the ball is zero since the ball is moving at constant speed.

Diagram showing energy transfers and transformations among and within objects in the scenario: In Fig. 18, boxes represent objects, letters represent units of energy ( $T$ indicates thermal energy, $K$ indicates kinetic energy, and $G$ indicates gravitational energy), and arrows represent energy transfers or transformations.

(Chemical energy in Taylor may transform into kinetic and/or thermal energy via metabolism or movement of Taylor's arm, but these processes are less central to this story.)

Evidence that each transfer or transformation has occurred:

- $G \rightarrow K$ : ball lowers via movement

- $K \rightarrow K$ : ball does work on hand as it moves

- $K \rightarrow T$ : kinetic energy turns to thermal energy via dissipative processes

Relationship between forces and energy: The normal force on the ball by Taylor-opposite the direction of motion of the ball-corresponds to the transfer of kinetic energy from the ball to Taylor. (One way to think about this is by imagining the corresponding force in the third law pair-the force on Taylor by the ball in the direction of motion. Contact forces are mechanisms of energy transfer.) The weight force on the ball by the Earth corresponds to the transformation of gravitational to kinetic energy in the ball.

Possible solution to the Sarah pushes a box free body diagram question: 
Free body diagram for box as it is being pushed: The box is in contact with Sarah, who pushes it, and the floor, which exerts both an upward normal force and a friction force that opposes the direction of motion of the box; these forces are depicted in the free body diagram for the box in Fig. 19. Because the box moves at constant speed on the flat (horizontal) floor, the magnitudes of the horizontal forces must be equal, as are the magnitudes of the vertical forces, by Newton's second law.

Diagram showing energy transfers and transformations among and within objects in the scenario: In Fig. 20, boxes represent objects, letters represent units of energy $(C$ indicates chemical energy, $T$ indicates thermal energy, and $K$ indicates kinetic energy), and arrows represent energy transfers or transformations. (Chemical energy in Sarah may transform into kinetic and/or thermal energy via metabolism or Sarah's movement, but these processes are less central to this story.)
Evidence that each transfer or transformation has occurred:

- $C \rightarrow K$ : Sarah's body moves via muscle contractions

- $K \rightarrow K$ : Sarah does work on the box as it moves; the box does work on floor as it moves (via frictional force)

- $K \rightarrow T$ : kinetic energy turns to thermal energy via dissipative processes

Relationship between forces and energy: The two horizontal forces in the free body diagram are associated with the kinetic energy transfers between Sarah and the box and between the box and the floor. Because the force by Sarah on the box is in the direction of motion, Sarah does work on the box, transferring energy to it; and because the force of friction opposes the motion, the box does work on the floor, transferring energy away from the box.
[1] A. R. Daane, S. Vokos, and R. E. Scherr, Learner understanding of energy degradation, in 2013 Physics Education Research Conference, edited by P. V. Englehardt, A. D. Churukian, and D. L. Jones (AIP, Portland, OR, 2013).

[2] A. A. diSessa, Toward an Epistemology of Physics, Cognit. Instr. 10, 105 (1993).

[3] E. Duckworth, "The Having of Wonderful Ideas" and Other Essays on Teaching and Learning, 3rd ed. (Teachers College Press, New York, NY, 2006).

[4] A. Elby, Helping physics students learn how to learn, Am. J. Phys. 69, S54 (2001).

[5] D. Hammer, Student Inquiry in a Physics Class Discussion, Cognit. Instr. 13, 401 (1995).

[6] D. Hammer, Student resources for learning introductory physics, Am. J. Phys. 68, S52 (2000).

[7] J. Dewey, Experience and Education (Simon and Schuster, Inc., New York, NY, 1938).

[8] R. Driver, R. Driver, H. Asoko, J. Leach, P. Scott, and E. Mortimer, Constructing scientific knowledge in the classroom, Educ. Res. 23, 5 (1994).

[9] R. Driver and B. Bell, Students' thinking and the learning of science: a constructivist view, Sch. Sci. Rev. 67, 443 (1986).

[10] E. von Glasersfeld, Learning as Constructive Activity, in Proceedings of the 5th Annual Meeting of the North American Group of Psychology in Mathematics Education, edited by J.C. Bergeron and N. Herscovics (PME-NA, Montreal, 1983), pp. 41-101.

[11] C. T. Fosnot, Constructivism: A Psychological Theory of Learning, in Constructivism: Theory, Perspectives, and Practice, edited by C. T. Fosnot (Teachers College Press, New York, NY, 1996), pp. 8-33.
[12] S. Carey, Cognitive science and science education, Am. Psychol. 41, 1123 (1986).

[13] R. Leinonen, M. A. Asikainen, and P. E. Hirvonen, Overcoming students' misconceptions concerning thermal physics with the aid of hints and peer interaction during a lecture course, Phys. Rev. ST Phys. Educ. Res. 9, 020112 (2013).

[14] M. McCloskey, Naive theories of motion, in Mental Models, edited by D. Gentner and A. Stevens (Erlbaum, Hillsdale, NJ, 1983), pp. 299-324.

[15] L. C. McDermott, Millikan Lecture 1990: What we teach and what is learned - Closing the gap, Am. J. Phys. 59, 301 (1991).

[16] G. J. Posner, K. A. Strike, P. W. Hewson, and W. A. Gertzog, Accommodation of a Scientific Conception: Toward a Theory of Conceptual Change, Sci. Educ. 66, 211 (1982).

[17] C. Singh, Student understanding of quantum mechanics, Am. J. Phys. 69, 885 (2001).

[18] C. Singh, Effect of misconception on transfer in problem solving, in Proceedings of the 2007 Physics Education Research Conference, edited by L. Hsu, C. Henderson, and L. McCullough (AIP Conference Proceedings, Melville, NY, 2007), Vol. 951, pp. 196-199.

[19] J. P. Smith III, A. A. diSessa, and J. Roschelle, Misconceptions reconceived: a constructivist analysis of knowledge in transition, J. Learn. Sci. 3, 115 (1994).

[20] D. Hammer, Student resources for learning introductory physics, Am. J. Phys. 68, S52 (2000).

[21] D. Hammer et al., Resources, Framing, and Transfer, in Transfer of Learning from a Modern Multidisciplinary Perspective, edited by J.P. Mestre (Information Age Publishing, Greenwich, 2005), pp. 89-119. 
[22] R. Driver, E. Guesne, and A. Tiberghein, Children's Ideas in Science (Open University Press, Philadelphia, PA, 1985).

[23] R. Driver et al., Making Sense of Secondary Science: Research Into Children's Ideas (Routledge, New York, NY, 1994).

[24] L. C. McDermott, Oersted Medal Lecture 2001: "Physics Education Research - The Key to Student Learning", Am. J. Phys. 69, 1127 (2001).

[25] L. Lising and A. Elby, The impact of epistemology on learning: A case study from introductory physics, Am. J. Phys. 73, 372 (2005).

[26] R. E. Scherr, Modeling student thinking: An example from special relativity, Am. J. Phys. 75, 272 (2007).

[27] P. R. L. Heron, Empirical investigations of learning and teaching, part I: Examining and interpreting student thinking, in Proceedings of the International School of Physics "Enrico Fermi," Course CLVI, edited by E. F. Redish and M. Vicentini (IOS Press, Amsterdam, 2004).

[28] L. McDermott, A view from physics, in Toward a Scientific Practice of Science Education, edited by M. Gardner, J. G. Greeno, F. Reif, A. H. Schoenfeld, A. diSessa, and E. Stage (Lawrence Erlbaum Associates, Hillsdale, NJ, 1990), pp. 3-30.

[29] A. D. Robertson and P. S. Shaffer, University student and K-12 teacher reasoning about the basic tenets of kineticmolecular theory, Part I: Volume of an ideal gas, Am. J. Phys. 81, 303 (2013).

[30] D. Hammer, More than misconceptions: Multiple perspectives on student knowledge and reasoning, and an appropriate role for education research, Am. J. Phys. 64, 1316 (1996).

[31] D. Hammer, F. Goldberg, and S. Fargason, Responsive teaching and the beginnings of energy in a third grade classroom, Rev. Sci. Math. ICT Educ. 6, 51 (2012).

[32] D. Hammer and E. van Zee, Seeing the Science in Children's Thinking: Case Studies of Student Inquiry in Physical Science (Heinemann, Portsmouth, NH, 2006).

[33] B. W. Harrer, V. J. Flood, and M. C. Wittmann, Productive resources in students' ideas about energy: An alternative analysis of Watts' original interview transcripts, Phys. Rev. ST Phys. Educ. Res. 9, 023101 (2013).

[34] A. Gupta, A. Elby, and L. D. Conlin, How substancebased ontologies for gravity can be productive: A case study, Phys. Rev. ST Phys. Educ. Res. 10, 010113 (2014).

[35] D. Hammer, Misconceptions or P-Prims: How May Alternative Perspectives of Cognitive Structure Influence Instructional Perceptions and Intentions?, J. Learn. Sci. 5, 97 (1996).

[36] P. R. L. Heron, Empirical investigations of learning and teaching, part II: Developing research-based materials, in Proceedings of the International School of Physics "Enrico Fermi," Course CLVI, edited by E. F. Redish and M. Vicentini (IOS Press, Amsterdam, 2004).

[37] K. M. Koenig, R. J. Endorf, and G. A. Braun, Effectiveness of different tutorial recitation teaching methods and its implications for TA training, Phys. Rev. ST Phys. Educ. Res. 3, 010104 (2007).
[38] K. Miller, N. Lasry, K. Chu, and E. Mazur, Role of physics lecture demonstrations in conceptual learning, Phys. Rev. ST Phys. Educ. Res. 9, 020113 (2013).

[39] D. L. Ball, With an Eye on the Mathematical Horizon: Dilemmas of Teaching Elementary School Mathematics, Elem. School J. 93, 373 (1993).

[40] D. E. Brown, Refocusing core intuitions: A concretizing role for analogy in conceptual change, J. Res. Sci. Teach. 30, 1273 (1993).

[41] J. Clement, Using bridging analogies and anchoring intuitions to deal with students' preconceptions in physics, J. Res. Sci. Teach. 30, 1241 (1993).

[42] A. diSessa, Momentum flow as an alternative perspective in elementary mechanics, Am. J. Phys. 48, 365 (1980).

[43] D. J. Grayson, Concept substitution: A teaching strategy for helping students disentangle related physics concepts, Am. J. Phys. 72, 1126 (2004).

[44] D. Hammer, Discovery Learning and Discovery Teaching, Cognit. Instr. 15, 485 (1997).

[45] P. Hutchison and D. Hammer, Attending to student epistemological framing in a science classroom, Sci. Educ. 94, 506 (2010).

[46] D. Levin et al., Becoming a Responsive Science Teacher: Focusing on Student Thinking in Secondary Science (National Science Teachers Association Press, Arlington, VA, 2012).

[47] J. Minstrell, Explaining the "at rest" condition of an object, Phys. Teach. 20, 10 (1982).

[48] R. S. Russ, R. E. Scherr, D. Hammer, and J. Mikeska, Recognizing Mechanistic Reasoning in Student Scientific Inquiry: A Framework for Discourse Analysis Developed From Philosophy of Science, Sci. Educ. 92, 499 (2008).

[49] R. Duit, Bibliography-Students' and Teachers' Conceptions and Science Education (2009), http://www.ipn .uni-kiel.de/aktuell/stcse/.

[50] L. C. McDermott, P. S. Shaffer, and the Physics Education Group at the University of Washington, Tutorials in Introductory Physics, preliminary 2nd ed. (Prentice Hall College Division, Englewood Cliffs, NJ, 2011).

[51] F. Goldberg et al., Physical Science and Everyday Thinking, 2nd ed., United States of America: It's About Time (Herff Jones Education Division, USA, 2009).

[52] T. P. Carpenter, E. Fennema, P. L. Peterson, C.-P. Chiang, and M. Loef, Using Knowledge of Children's Mathematics Thinking in Classroom Teaching: An Experimental Study, Am. Educ. Res. J. 26, 499 (1989).

[53] E. Fennema, T. P. Carpenter, M. L. Franke, L. Levi, V. R. Jacobs, and S. B. Empson, A Longitudinal Study of Learning to Use Children's Thinking in Mathematics Instruction, J. Res. Math. Educ. 27, 403 (1996).

[54] E. Fennema, M. L. Franke, T. P. Carpenter, and D. A. Carey, Using Children's Mathematical Knowledge in Instruction, Am. Educ. Res. J. 30, 555 (1993).

[55] J. L. Pierson, The Relationship Between Patterns of Classroom Discourse and Mathematics Learning (University of Texas at Austin, Austin, TX, 2008), p. 161.

[56] S. B. Empson and V. R. Jacobs, Learning to Listen to Children's Mathematics, in Tools and Processes in Mathematics Teacher Education, edited by D. Tirosh 
and T. Wood (Sense Publishers, Netherlands, 2008), pp. 257-281.

[57] F. Goldberg, Responsive Teaching and the Emergence of Energy Ideas in Third Grade Classrooms, in UW/SPU Speaker Series (Seattle, WA, 2012).

[58] N. B. Kersting, K. B. Givvin, F. L. Sotelo, and J. W. Stigler, Teachers' Analyses of Classroom Video Predict Student Learning of Mathematics: Further Explorations of a Novel Measure of Teacher Knowledge, J. Teach. Educ. 61, 172 (2010).

[59] J. Hiebert and D. Wearne, Instructional tasks, classroom discourse, and students' learning in second-grade arithmetic, Am. Educ. Res. J. 30, 393 (1993).

[60] G. B. Saxe, M. Gearhart, and M. Seltzer, Relations between Classroom Practices and Student Learning in the Domain of Fractions, Cognit. Instr. 17, 1 (1999).

[61] D. Schifter, Examining the Behavior of Operations: Noticing Early Algebraic Ideas, in Mathematics Teacher Noticing: Seeing Through Teachers' Eyes, edited by M. G. Sherin, V. R. Jacobs, and R. A. Philipp (Routledge, New York, NY, 2011), pp. 204-220.

[62] J. Richards, Exploring what stabilizes teachers' attention and responsiveness to the substance of students' scientific thinking in the classroom (University of Maryland at College Park, 2013).

[63] J. E. Coffey, D. Hammer, D. M. Levin, and T. Grant, The Missing Disciplinary Substance of Formative Assessment, J. Res. Sci. Teach. 48, 1109 (2011).

[64] J. L. Lemke, Talking Science: Language, Learning, and Values (Ablex Publishing, Norwood, NJ, 1990).

[65] K. Gallas, Talking Their Way Into Science: Hearing Children's Questions and Theories, Responding with Curricula (Teachers College Press, New York, NY, 1995).

[66] M. P. Jiménez-Aleixandre, A. B. Rodríguez, and R. A. Duschl, "Doing the Lesson" or "Doing Science": Argument in High School Genetics, Sci. Educ. 84, 757 (2000).

[67] R. A. Engle and F. R. Conant, Guiding Principles for Fostering Productive Disciplinary Engagement: Explaining an Emergent Argument in a Community of Learners Classroom, Cognit. Instr. 20, 399 (2002).

[68] S. B. Empson, Low-performing students and teaching fractions for understanding: An interactional analysis, J. Res. Math. Educ. 34, 305 (2003).

[69] J. Hudicourt-Barnes, The Use of Argumentation in Haitian Creole Science Classrooms, Harv. Educ. Rev. 73, 73 (2003).

[70] B. Warren, C. Ballenger, M. Ogonowski, A. S. Rosebery, and J. Hudicourt-Barnes, Rethinking Diversity in Learning Science: The Logic of Everyday Sense-Making, J. Res. Sci. Teach. 38, 529 (2001).

[71] S. Michaels, Can the Intellectual Affordances of Working-Class Storytelling Be Leveraged in School?, Hum. Dev. 48, 136 (2005).

[72] A. S. Rosebery, M. Ogonowski, M. DiSchino, and B. Warren, "The Coat Traps All Your Body Heat": Heterogeneity as Fundamental to Learning, J. Learn. Sci. 19, 322 (2010).
[73] B. Warren, M. Ogonowski, and S. Pothier, "Everyday", and "Scientific": Rethinking Dichotomies in Modes of Thinking in Science Learning, in Everyday Matters in Science, and Mathematics, edited by R. Nemirovsky et al. (Lawrence Erlbaum, Mahwah, NJ, 2005).

[74] R. S. Russ, J. E. Coffey, D. Hammer, and P. Hutchison, Making classroom assessment more accountable to scientific reasoning: A case for attending to mechanistic thinking, Sci. Educ. 93, 875 (2009).

[75] A. D. Robertson et al., What is Responsive Teaching?, in Responsive Teaching in Science and Mathematics, edited by A. D. Robertson, R.E. Scherr, and D. Hammer (Routledge, New York, NY, 2016), pp. 1-35.

[76] D. Hammer, The variability of student reasoning, lectures 1-3, in Proceedings of the Enrico Fermi Summer School, Course CLVI, edited by E. F. Redish and M. Vicentini (Italian Physical Society, Bologna, 2004), pp. 279-340.

[77] R. Donmoyer, Generalizability and the Single-Case Study, in Qualitative Inquiry in Education: The Continuing Debate, edited by E. W. Eisner and A. Peshkin (Teachers College Press, New York, 1990), pp. 175-200.

[78] T. D. Cook, Randomized Experiments in Educational Policy Research: A Critical Examination of the Reasons the Educational Evaluation Community has Offered for not Doing Them, Educ. Eval. Policy Anal. 24, 175 (2002).

[79] N. R. Council, Scientific Research in Education, C.o.S.P.f.E. Research, edited by R. J. Shavelson and L. Towne (Center for Education, Division of Behavioral and Social Sciences and Education, Washington, DC, 2002).

[80] L. S. Shulman, Those who understand: Knowledge growth in teaching, Educ. Res. 15, 4 (1986).

[81] L. S. Shulman, Knowledge and Teaching: Foundations of the New Reform, Harv. Educ. Rev. 57, 1 (1987).

[82] P. L. Grossman, The Making of a Teacher: Teacher Knowledge and Teacher Education (Columbia University, Teachers College Press, New York, 1990).

[83] D. L. Ball and H. Bass, Toward a practice-based theory of mathematical knowledge for teaching, in Proceedings of the 2002 Annual Meeting of the Canadian Mathematics Education Study Group, edited by B. Davis and E. Simmt (CMESG/GCEDM, Edmonton, Alberta, 2003), pp. 3-14.

[84] D. L. Ball, M. H. Thames, and G. Phelps, Content Knowledge for Teaching: What Makes It Special?, J. Teach. Educ. 59, 389 (2008).

[85] J. R. Thompson, W. M. Christensen, and M. C. Wittmann, Preparing future teachers to anticipate student difficulties in physics in a graduate-level course in physics, pedagogy, and action research, Phys. Rev. ST Phys. Educ. Res. 7, 010108 (2011)

[86] B. T. Spike and N. D. Finkelstein, Preparing tutorial and recitation instructors: A pedagogical approach to focusing attention on content and student reasoning, Am. J. Phys. 80, 1020 (2012).

[87] E. Etkina, Pedagogical content knowledge and preparation of high school physics teachers, Phys. Rev. ST Phys. Educ. Res. 6, 020110 (2010).

[88] J. A. Maxwell, Understanding and Validity in Qualitative Research, Harv. Educ. Rev. 62, 279 (1992). 
[89] NGSS Lead States, Next Generation Science Standards: For States, By States (National Academies Press, Washington, DC, 2013).

[90] B. W. Dreyfus, B. D. Geller, J. Gouvea, V. Sawtelle, C. Turpen, and E. F. Redish, Ontological metaphors for negative energy in an interdisciplinary context, Phys. Rev. ST Phys. Educ. Res. 10, 020108 (2014).

[91] B. W. Dreyfus, J. Gouvea, B. D. Geller, V. Sawtelle, C. Turpen, and E. F. Redish, Chemical energy in an introductory physics course for the life sciences, Am. J. Phys. 82, 403 (2014).

[92] B. W. Dreyfus, E. F. Redish, and J. Watkins, Student Views of Macroscopic and Microscopic Energy in Physics and Biology, in Proceedings of the 2011 Physics Education Research Conference, edited by N. S. Rebello, P. V. Engelhardt, and C. Singh (AIP, Melville, NY, 2012), pp. 179-182.

[93] B. W. Dreyfus et al., Students' reasoning about "highenergy bonds" and ATP: A vision of interdisciplinary education, Phys. Rev. ST Phys. Educ. Res. 10, 050115 (2014).

[94] N. R. Council, Bio 2010: Transforming Undergraduate Education for Future Research Biologists (National Academies Press, Washington, DC, 2003).

[95] L. M. Goodhew and A. D. Robertson, Investigating the Relationship Between the Substance Metaphor for Energy and Its Proposed Affordances and Limitations, in Proceedings of the 2014 Physics Education Research Conference, edited by P. V. Englehardt, A. D. Churukian, and D. L. Jones (AIP, Melville, NY, 2015), pp. 103-106.

[96] L. M. Goodhew and A. D. Robertson, Connecting Students' Ideas to the Discipline - One Role of Content Knowledge in Responsive Teaching: Case Studies from K-12 Classroom Discussions of Energy, Phys. Rev. Phys. Educ. Res. (to be published).

[97] R. E. Scherr, H. G. Close, E. W. Close, V. J. Flood, S. B. McKagan, A. D. Robertson, L. Seeley, M. C. Wittmann, and S. Vokos, Negotiating energy dynamics through embodied action in a materially structured environment, Phys. Rev. ST Phys. Educ. Res. 9, 020105 (2013).

[98] R. E. Scherr and A. D Robertson, The productivity of "collisions generate heat" for reconciling an energy model with mechanistic reasoning: A case study, Phys. Rev. ST Phys. Educ. Res. 11, 010111 (2015).

[99] A. D. Robertson et al., Toward a practice-based theory of content knowledge for teaching energy in high school physics, Phys. Rev. Phys. Educ. Res. (to be published).

[100] R. E. Scherr et al., Content knowledge for teaching energy: An example from middle-school science, in 2013 Physics Education Research Conference (AIP, Melville, NY, 2013).

[101] D. M. Watts, Some alternative views of energy, Phys. Educ. 18, 213 (1983).

[102] R. Trumper, Being constructive: an alternative approach to the teaching of the energy concept—part two, Int. J. Sci. Educ. 13, 1 (1991).

[103] R. Trumper, Being constructive: an alternative approach to the teaching of the energy concept - part one, Int. J. Sci. Educ. 12, 343 (1990).

[104] J. Solomon, Learning about energy: how pupils think in two domains, Int. J. Sci. Educ. 5, 49 (1983).
[105] J. Radoff et al., The Beginnings of Energy in Third Graders' Reasoning, in Procedings of the 2010 Physics Education Research Conference, edited by C. Singh, M. Sabella, and N. S. Rebello (AIP, Portland, OR, 2010), pp. 269-272.

[106] J. Bliss and J. Ogborn, Children's choices of uses of energy, Eur. J. Sci. Educ. 7, 195 (1985).

[107] R. Driver et al., Energy, in Making Sense of Secondary Science: Research into Children's Ideas (Routledge, New York, NY, 1994), pp. 143-147.

[108] R. Duit, Learning the energy concept in school empirical results from The Philippines and West Germany, Phys. Educ. 19, 59 (1984).

[109] G. Lee and J. Yi, Addressing Students' Difficulties in Understanding Two Different Expressions of Gravitational Potential Energy (I): $\mathrm{mgh}$, and $-\mathrm{GMm} / \mathrm{r}$, in Proceedings of the 2006 Physics Education Research Conference, edited by L. McCullough, L. Hsu, and P. Heron (AIP, Melville, NY, 2007), pp. 165-168.

[110] M. E. Loverude, Student Understanding of Gravitational Potential Energy, and the Motion of Bodies in a Gravitational Field, in Proceedings of the 2004 Physics Education Research Conference, edited by J. Marx, P. Heron, and S. Franklin (AIP, Melville, NY, 2005), pp. $77-80$.

[111] R. Driver and L. Warrington, Students' use of the principle of energy conservation in problem situations, Phys. Educ. 20, 171 (1985).

[112] J. Solomon, Teaching the conservation of energy, Phys. Educ. 20, 165 (1985).

[113] T. G. Amin, Conceptual Metaphor Meets Conceptual Change, Hum. Dev. 52, 165 (2009).

[114] E. Brewe, Energy as a substancelike quantity that flows: Theoretical considerations and pedagogical consequences, Phys. Rev. ST Phys. Educ. Res. 7, 020106 (2011).

[115] R. E. Scherr, H. G. Close, S. B. McKagan, and S. Vokos, Representing energy. I. Representing a substance ontology for energy, Phys. Rev. ST Phys. Educ. Res. 8, 020114 (2012).

[116] M. E. Loverude, Do students conceptualize energy as a material substance?, in Proceedings of the 2002 Physics Education Research Conference, edited by S. Franklin, K. Cummings, and J. Marx (AIP Melville, NY, 2002).

[117] R. Trumper, A Longitudinal Study of Physics Students' Conceptions of Energy in Pre-Service Training for High School Teachers, J. Sci. Educ. Technol. 7, 311 (1998).

[118] R. Trumper, A survey of conceptions of energy of Israeli pre-service high school biology teachers, Int. J. Sci. Educ. 19, 31 (1997).

[119] J. Solomon, Messy, contradictory and obstinately persistent: a study of children's out-of-school ideas about energy, Sch. Sci. Rev. 65, 225 (1983).

[120] R. E. Scherr, H. G. Close, E. W. Close, and S. Vokos, Representing energy. II. Energy tracking representations, Phys. Rev. ST Phys. Educ. Res. 8, 020115 (2012).

[121] R. Duit, Should energy be illustrated as something quasimaterial?, Int. J. Sci. Educ. 9, 139 (1987). 
[122] R. P. Feynman, R. B. Leighton, and M. Sands, The Feynman Lectures on Physics (Addison-Wesley, Reading, MA, 1963), Vol. 1.

[123] A. Gupta, D. Hammer, and E. F. Redish, The Case for Dynamic Models of Learners' Ontologies in Physics, J. Learn. Sci. 19, 285 (2010).

[124] A. R. Daane, S. Vokos, and R. E. Scherr, Conserving energy in physics and society: Creating an integrated model of energy and the second law of thermodynamics, in Proceedings of the 2012 Physics Education Research Conference, edited by N.S. Rebello, P. Engelhardt, and A. D. Churukian (AIP, Melville, NY, 2012), pp. 114-117.

[125] R. Duit, Energy Conceptions Held by Students, and Consequences for Science Teaching, in Proceedings of the International Seminar "Misconceptions in Science, and Mathematics”, edited by H. Helm and J. D. Novak (Cornell University, Ithaca, NY, 1983), pp. 316-321.

[126] M. Vigeant et al., Repairing Engineering Students' Misconceptions about Energy and Thermodynamics, in Teaching and Learning of Energy in K-12 Education, edited by R.F. Chen et al. (Springer International Publishing, Switzerland, 2014), pp. 223-236.

[127] A. Sağlam-Arslan, Cross-Grade Comparison of Students' Understanding of Energy Concepts, J. Sci. Educ. Technol. 19, 303 (2010).

[128] A. Sağlam-Arslan and M. A. Kurnaz, Prospective physics teachers' level of understanding energy, power, and force concepts, Asia-Pacific Forum on Sci. Learn. Teach. 10, 1 (2009).

[129] L. Seeley, Assessing for shifts in learner's energy reasoning strategies, in Proceedings of the 2013 Physics Education Research Conference, edited by P. Engelhardt, A. D. Churukian, and D. L. Jones (AIP, Melville, NY, 2014), pp. 337-340.

[130] E. F. Redish, A Theoretical Framework for Physics Education Research: Modeling Student Thinking, in Proceedings of the Enrico Fermi Summer School, Course CLVI, edited by E. Redish and M. Vicentini (Italian Physical Society, Bologna, 2004).
[131] R. F. Bornstein, Face Validity, in The SAGE Encyclopedia of Social Science Research Methods, edited by M.S. Lewis-Beck, A. Bryman, and T. F. Liao (Sage Publications, Thousand Oaks, CA, 2004), pp. 368-369.

[132] K. Krippendorff, Content Analysis: An Introduction to Its Methodology, 3rd ed. (Sage Publications, Thousand Oaks, CA, 2013).

[133] C. Singh and D. Rosengrant, Students' conceptual knowledge of energy and momentum, in Proceedings of the 2001 Physics Education Research Conference, edited by K. Cummings, S. Franklin, and J. Marx (AIP, Melville, NY, 2001).

[134] A. R. Daane, L. Wells, and R. E. Scherr, Energy Theater, Phys. Teach. 52, 291 (2014).

[135] R. E. Scherr et al., Energy Tracking Diagrams, Phys. Teach. 54, 96 (2016).

[136] R. Bresser and S. Fargason, Becoming Scientists: InquiryBased Teaching in Diverse Classrooms, Grades 3-5 (Stenhouse Publishers, Portland, ME, 2013).

[137] L. Jaber, Attending to students' epistemic affect, in Responsive Teaching in Science, edited by A.D. Robertson, R. E. Scherr, and D. Hammer (Routledge, New York, NY, 2016), pp. 162-188.

[138] A. C. Maskiewicz and V. A Winters, Understanding the Co-Construction of Inquiry Practices: A Case Study of a Responsive Teaching Environment, J. Res. Sci. Teach. 49, 429 (2012).

[139] J. W. Willis, World Views, Paradigms, and the Practice of Social Science Research, in Foundations of Qualitative Research: Interpretive and Critical Approaches (Sage Publications, Thousand Oaks, CA, 2007).

[140] L. J. Atkins and B. W. Frank, Examining the products of responsive inquiry, in Responsive Teaching in Science and Mathematics, edited by A. D. Robertson, R. E. Scherr, and D. Hammer (to be published).

[141] P. R. L. Heron, Effect of lecture instruction on student performance on qualitative questions, Phys. Rev. ST Phys. Educ. Res. 11, 010102 (2015). 